US Army Corps

of Engineers ${ }_{\circledast}$

Engineer Research and

Development Center

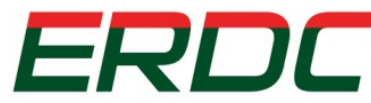

INNOVATIVE SOLUTIONS for a safer, better world

Human Infrastructure System Assessment for Military Operations

\title{
Assessing Socioeconomic Impacts of Cascading Infrastructure Disruptions in a Dynamic Human-Infrastructure Network
}

Liqun Lu, Xin Wang, Zhaodong Wang, Yanfeng Ouyang, Jeanne Roningen, Scott Tweddale, Patrick Edwards, and Natalie Myers

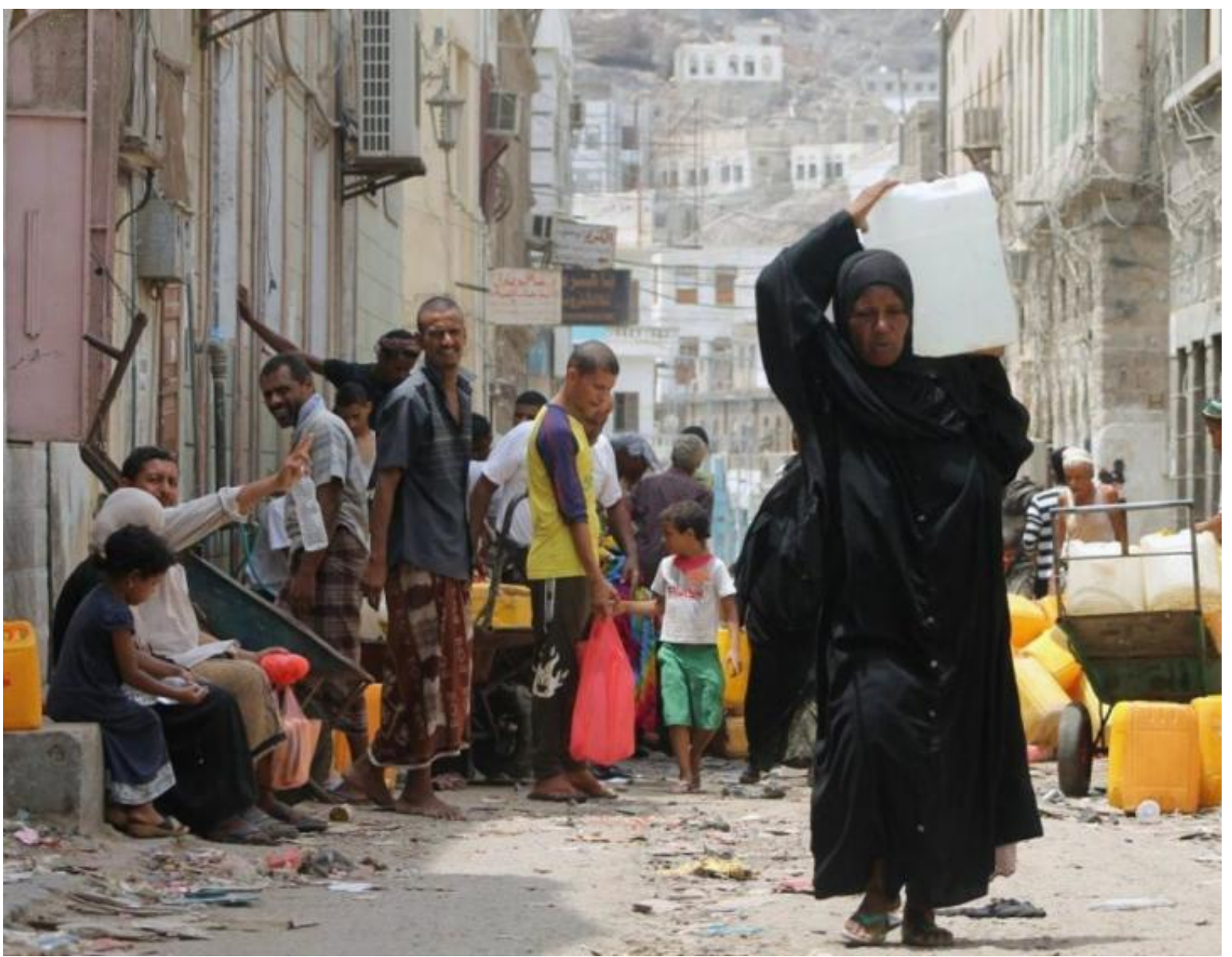


The U.S. Army Engineer Research and Development Center (ERDC) solves the nation's toughest engineering and environmental challenges. ERDC develops innovative solutions in civil and military engineering, geospatial sciences, water resources, and environmental sciences for the Army, the Department of Defense, civilian agencies, and our nation's public good. Find out more at www.erdc.usace.army.mil.

To search for other technical reports published by ERDC, visit the ERDC online library at http://acwc.sdp.sirsi.net/client/default. 


\section{Assessing Socioeconomic Impacts of Cascading Infrastructure Disruptions in a Dynamic Human- Infrastructure Network}

Scott Tweddale, Patrick Edwards, Natalie Myers

Construction Engineering Research Laboratory

U.S. Army Engineer Research and Development Center

2902 Newmark Drive

Champaign, IL 61822

Jeanne Roningen

Cold Regions Research and Engineering Laboratory

U.S. Army Engineer Research and Development Center

72 Lyme Road

Hanover, NH 03755-1290

Liqun Lu, Xin Wang, Zhaodong Wang, Dr. Yanfeng Ouyang,

University of Illinois at Urbana-Champaign

Department of Civil and Environmental Engineering

205 N Mathews Ave.

Urbana IL 61801-2352

Final report

Approved for public release; distribution is unlimited.

Prepared for Assistant Secretary of the Army for Acquisition, Logistics, and Technology 103 Army Pentagon

Washington, DC 20314-1000

Under Project No. 405479, "Human Infrastructure System Assessment for Military Operations" 


\section{Abstract}

The functionality of modern cities relies heavily on interdependent infrastructure systems such as those for water, power, and transportation. Disruptions often propagate within and across physical infrastructure networks and result in catastrophic consequences. The reaction of communities to disasters (e.g., seeking alternatives) may further transfer and aggravate the burden on surviving infrastructures, which may facilitate cascading secondary disruptions. Hence, a holistic analysis framework that integrates infrastructure interdependencies and community behaviors is needed to evaluate a city's vulnerability to disruptions and to assess the impact of a disaster. U.S. Army doctrine requires that commanders understand, visualize, and describe the infrastructure component of the Joint Operating Environment to accomplish the Army's missions of protecting, restoring, and developing infrastructure. To this end, a game-theoretical equilibrium model has been developed in a multilayer infrastructure network, to systematically investigate the mutual influence between the infrastructures and the communities. In this model, two types of infrastructure failure patterns are formulated to capture general network interdependencies; network equilibrium is extended into infrastructure and community systems to address redistribution of demand for life-supporting resources; the societal impact of disasters is estimated based on resource demand loss, cost increase, and total infrastructure failure. A real-world case study was implemented to demonstrate the proposed model and algorithm, and to reveal insights. 


\section{Contents}

Abstract................................................................................................................................. if

Figures and Tables..............................................................................................................v

Abbreviations.................................................................................................. vi

Preface ..................................................................................................................................vif

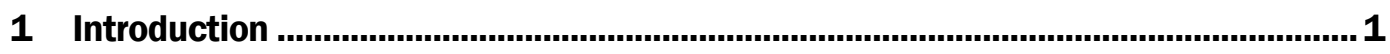

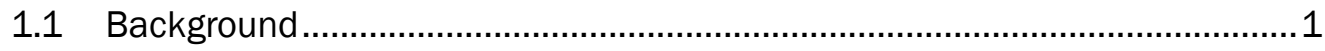

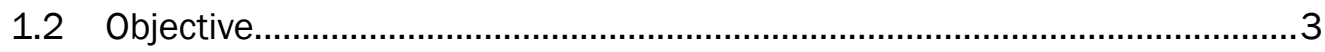

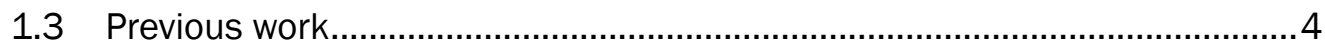

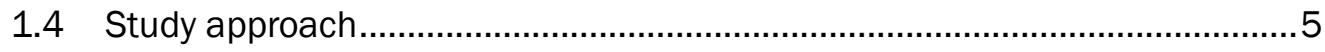

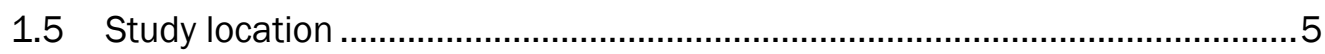

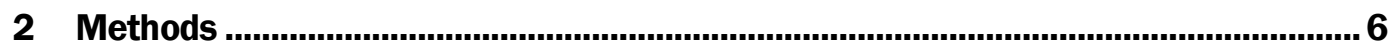

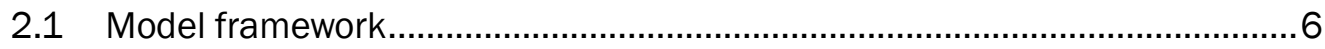

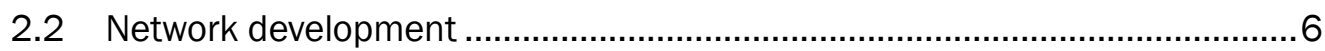

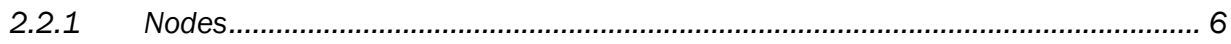

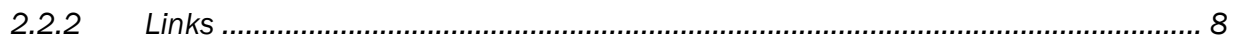

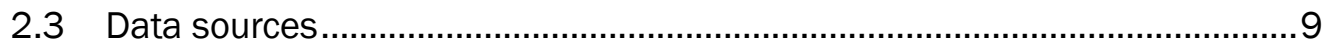

2.3.1 Urban Tactical Planner ..................................................................................... 10

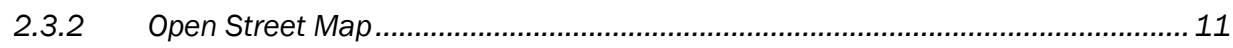

2.4 Conceptual model construction.......................................................... 12

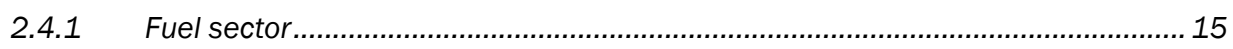

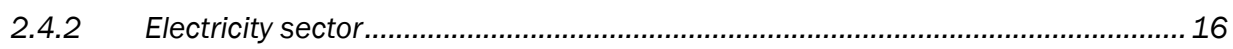

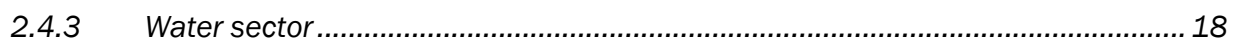

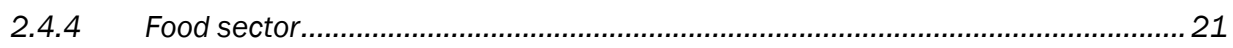

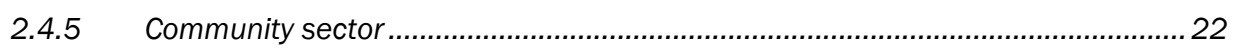

2.4.6 Transportation sector ........................................................................................... 25

2.5 Translation of conceptual model to network model input........................... 26

2.6 Alpha model development ............................................................. 26

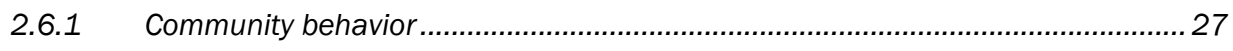

2.6.2 Disruption propagation mechanism ................................................................. 29

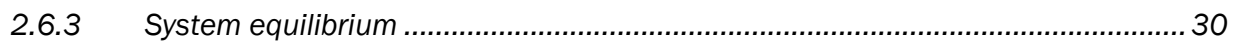

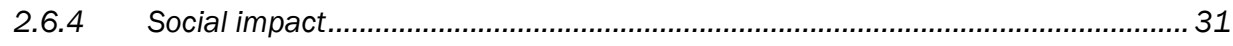

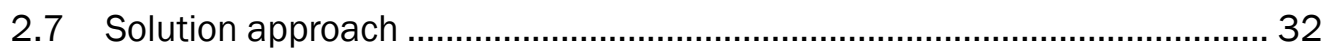

2.8 Alternative model formulations........................................................ 34

2.8.1 Probabilistic failure using Monte-Carlo simulations............................................... 34

2.8.2 Restore, recover, and rebuild using the genetic algorithm .................................. 35

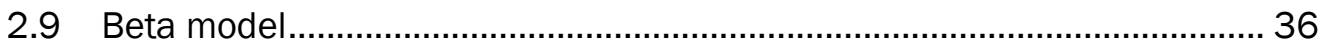

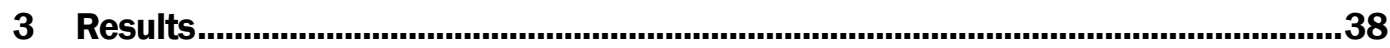

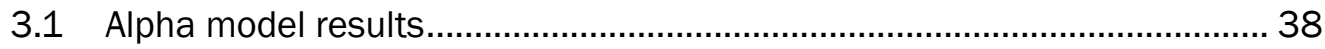




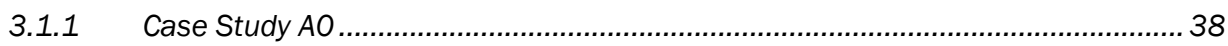

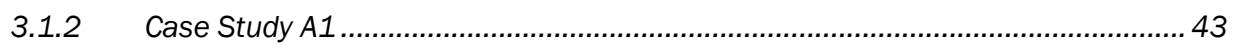

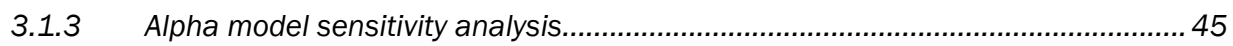

3.2 Alternative model results .......................................................... 48

3.2.1 Probabilistic failure with Monte-Carlo simulation...................................................48

3.2.2 Restore, recover, and rebuild using the genetic algorithm ................................. 49

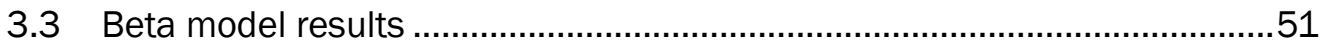

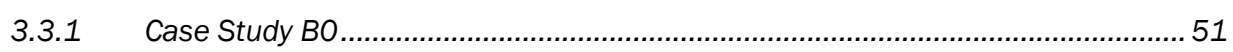

3.3.2 Beta model sensitivity analysis ................................................................. 52

4 Conclusions .........................................................................................................55

References..................................................................................................................... 57

\section{Report Documentation Page}




\section{Figures and Tables}

\section{Figures}

Figure 1. Example of linked infrastructure nodes, by sector, with community endusers.

Figure 2. Left: In strong support, if one of the three required inputs to the top infrastructure component fails, then that results in the failure of the downstream component itself. Right: In weak support, the failure of one resource simply means that the downstream component can choose from among alternative sources, and that the downstream component will only fail if the access costs for all available sources are higher than some predefined threshold.

Figure 3. The conceptual infrastructure network model for Maiduguri. Colored boxes represent types of nodes in the network; solid black lines and arrows indicate strong support; dashed black lines indicate weak support. Semitransparent nodes have not yet been represented in the model (ERDC-CERL).

Figure 4: Example package of sachet water (https://udeozochibuzo.wordpress.com/2014/01/14/cash-spiner- polyethyleneor-sachets-printing-business/).

Figure 5: Imagery shows the agricultural area northeast of Maiduguri's urban area during April 2014 (top) and November 2013 (bottom). Fields and orchards that are green during the dry season have year-round access to irrigation, either via wells or via surface water.

Figure 6. Augmented network representation...................................................................

Figure 7. Maiduguri community and population distribution.............................................39

Figure 8. Maiduguri infrastructure distribution..................................................................40

Figure 9. Status of infrastructure components after a cascading disruption. .....................41

Figure 10. Community water costs before (top) and after (bottom) disruption. .................42

Figure 11. Initial water access costs in case study A1 .................................................44

Figure 12. Water access cost ratio, final, case study A1 . ..............................................45

Figure 13. Medical facilities access costs under Repair-Restore-Rebuild scenario, (a) prior to disruption (low costs), (b) after disruption (high costs), (c) after restoration of one previously existing facility (moderate costs), (d) after rebuilding in two new locations (relatively low costs) as optimized using the genetic algorithm. Note that image colors are scaled differently between the scenarios, but always with light blue representing the lowest cost and bright pink representing the highest cost.

Figure 14. Water access cost ratios for Beta Model, Scenario 0.

\section{Tables}

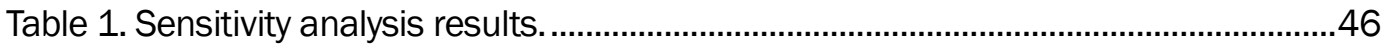

Table 2. Number of facility failures, by sector, under probabilistic failure scenario. ..........48

Table 3. Societal impacts in the food and water sectors under different scenarios, using the Beta Model. 


\section{Abbreviations}

$\begin{array}{ll}\text { Term } & \text { Meaning } \\ \text { BTZ } & \text { built-up terrain zone } \\ \text { CAC } & \text { common access card } \\ \text { DoD } & \text { Department of Defense } \\ \text { FOUO } & \text { For Official Use Only } \\ \text { GIS } & \text { geographic information systems } \\ \text { GUI } & \text { graphical user interface } \\ \text { HISA } & \text { Human Infrastructure System Assessment } \\ \text { IDP } & \text { internally displaced person } \\ \text { ORNL } & \text { Oak Ridge National Laboratory } \\ \text { OSM } & \text { Open Street Map } \\ \text { USD } & \text { U.S. dollar } \\ \text { UTP } & \text { urban technical planner }\end{array}$




\section{Preface}

This study was conducted for the Assistant Secretary of the Army for Acquisition, Logistics, and Technology (ASAALT) under Project No. 405479, "Human Infrastructure System Assessment for Military Operations." The technical monitor was Mr. Ritchie L. Rodebaugh of the U.S. Army Engineer Research and Development Center's technical transfer office (CEERD-TZ-T).

The work was performed by the Ecological Processes Branch (CNN) of the Installation Division (CN), U.S. Army Engineer Research and Development Center, Construction Engineering Research Laboratory (ERDC-CERL). At the time of publication, Dr. Chris C. Rewerts was Chief, CEERD-CNN; Ms. Michelle Hanson was Chief, CEERD-CN; and Mr. Ritchie L. Rodebaugh, CEERD-TZ-T was the Technical Director for Geospatial Research and Engineering. The Deputy Director of ERDCCERL was Dr. Kirankumar Topudurti, and the Director was Dr. Ilker Adiguzel.

COL Bryan S. Green was the Commander of ERDC, and Dr. Jeffery P. Holland was the Director. 
(This page intentionally blank.) 


\section{Introduction}

\subsection{Background}

Modern cities are comprised of complex infrastructure networks such as those for power, water, transportation, which interact with one another and jointly function to provide resources and services to city residents. As cities continue to expand and prosper, the ever-growing population imposes pressing challenges to the urban infrastructure systems in every aspect. Even for properly designed infrastructures that satisfy people's needs in normal functioning scenarios, infrastructure performance is often vulnerable to unexpected disruptions due to factors such as natural disasters or hostile human activities. In such situations, the performance of the city and the well-being of the society can be significantly impacted, resulting in social disruptions related to economic loss, humanitarian crisis, and demographic loss.

Many events in recent years have evidenced that infrastructure failures, especially those under cascading propagations, can lead to catastrophic consequences. A well-known example is the Northeastern blackout in the United States and Canada in 2003. The power outage started in Ohio and then propagated to several nearby states and the province of Ontario, Canada. It eventually affected over 50 million people and led to a total estimated economic loss of $\$ 4.5$ to $\$ 8.2$ billion in the United States alone (Electricity Consumers Resource Council 2004) Thus, the impact of the blackout spread far beyond the power system. First, water supply systems were impacted, resulting in boil water advisories across many regions (Johnson and Lefebvre 2003). The boil advisories were mainly due to back-flows in the water treatment systems when the pumps failed to provide sufficient water pressure in the absence of a power supply. Second, in Ontario, regional gas station failures occurred due to malfunctioning pumps and, consequently, many long queues were observed at the remaining working gas stations and fuel prices skyrocketed (Public Safety 2006). Third, studies also showed that in areas such as New York City, hospital admissions and healthcare emergency calls increased significantly during the blackout due to many kinds of induced incidents (Prezant et al. 2005 and Lin et al. 2011). 
The existence of complex interdependencies across multiple infrastructure systems is one cause of the fragility in urban systems under disruption. Depending on the geographical location and function, each infrastructure's functionality relies on other infrastructures maintaining their functionality. Particularly, interdependencies exist among components (a) within the same infrastructure network (e.g., water treatment plants provide resources to downstream water storage facilities), and (b) across different infrastructure networks (e.g., power plants generate electricity for water pumps, traffic lights, and fuel refineries).

Urban infrastructure failures are likely to stimulate strong reactions from the population. A direct consequence of most system failure is difficulty for residents to access life-supporting resources. For example, people may have to line up at gas stations to purchase over-priced fuel, travel a longer distance to access water, or turn to diesel generators when the power grid is disrupted.

In reality, infrastructure failure and community reactions are mutually dependent, which further complicates the problem. For example, people may have to travel through the transportation network to deliver or retrieve resources, while some infrastructural interdependencies are realized by delivering commodity from one facility to another via transportation. When congestion increases due to people's response to system failure, the fluidity of commodity flow may be compromised and the cascading effect could be further exacerbated. Therefore, instead of allowing only one-directional impacts from system failure to population response, the impacts of human activities on physical system performances should also be considered.

Infrastructure is now recognized as one of the military's Joint Operational Variables and Joint doctrine-specified missions to restore essential services and to repair and protect critical infrastructure. Furthermore, in the recently released "Army Operating Concept, Win in a Complex World 2020-2040," infrastructure plays a key role in the descriptions of how landpower is leveraged to achieve national strategic objectives (U.S. Army 2014). Doctrine now demands that commanders and staff understand, visualize, and describe the infrastructure operating variable to accomplish missions involving selective targeting, protecting, restoring, and developing infrastructure in combat, stability, humanitarian assistance, and disaster relief operations. Current doctrine, however, does not say how 
commanders and staff are to approach these challenging tasks. Current infrastructure and societal models do not, by themselves, provide meaningful representation of the relationships between infrastructure and populations. This shortfall is a concern for both military and civil society, and the development of models shall work equally well in both (Myers et al. in process).

\subsection{Objective}

The overall objective of the Human Infrastructure System Assessment for Military Operations (HISA) research package is to develop analysis methods to account for both the physical/functional and social effects of infrastructure changes on sub-populations.

A goal is to build a model that represents combined human-infrastructure systems so that the potential impacts of infrastructure changes on social well-being in Army-relevant contexts can be explored. This model will be designed to provide possible policy insights into how best to protect crucial infrastructures, reserve emergency supplies, and avoid humanitarian disasters. Example applications of the model are summarized in the three following scenarios:

- Destroy. If infrastructure $\mathrm{X}$ is damaged or destroyed, how are other infrastructures affected and what are the effects on end-users in the community? Can these effects be represented in a way that allows negative impacts on local populations to be visualized and, as a result, to be managed appropriately?

- Protect. What infrastructure components are the most important to preserve or defend during an operation if the well-being of a particular community is to be prioritized?

- Restore. Given limitations on the number of nodes that can be repaired or rebuilt in a given time frame, how can repairs or rebuilds be prioritized to have the highest impact (both immediate and long-term) on local communities?

The objective of the subset of research summarized in the current report is to develop and test a network interdependency model that provides quantitative geospatial representations of socioeconomic impacts of changes to 
or failures within an infrastructure system, while considering that population reactions to infrastructure failures may change demand patterns, which themselves affect the entire system.

\subsection{Previous work}

Complex infrastructure interdependencies have been studied by a number of researchers. Rinaldi et al.(2001) discuss the challenge of modeling and simulating the system with a detailed analysis of four interdependency categories. Zhang and Peeta (2011) review work addressing infrastructural interdependencies with different approaches and propose a method of using computable general equilibrium theory to generalize the interdependencies. Focusing on different types of interdependencies, Motter and Lai (2002) and Buldyrev et al. (2010) respectively performed analytical studies and proved that disruptions at a small number of components can lead to disastrous cascading failure in the system. Moreover, efforts have been made to build more resilient systems (e.g., facility location and design chosen to optimize reliable service) based on an understanding of the interdependencies. For example, Wang and Ouyang (2013) describe the geographical interdependencies of demand among facilities and developed game-theoretic models to find an optimal spatial distribution of service facilities; Xie, et al. (2015) proposed a novel network augmentation approach that has a proven ability to decompose any infrastructure disruption interdependencies, such that the optimal design problem can be formulated and solved equivalently with only independent disruptions.

A number of recent studies have also focused on the social impacts caused by people's behavior. Horner and Widener (2011) first considered the impact of a transportation network failure on people accessing disaster relief goods after a hurricane, and then tried to optimize the location of commodity distribution facilities. Many efforts have been made to model community behaviors following an emergency or a disaster. A game-theoretical model such as Nash competition has been used to capture people's reaction to scarcity of resources. In particular, it is probably reasonable to assume that each community or individual would try to acquire resources with the least time and monetary cost, taking into account the peer reactions. Such a situation, often referred to as "equilibrium," changes dramatically after infrastructure failure, and those changes help to evaluate the social impact of that failure. Such game-theoretical models have been applied in related literature, e.g., within the scope of input-output models 
(Haimes and Jiang 2001; Haimes et al. 2005). Zhang and Peeta (2011) further considered an equilibrium that took into account both spatial and economic factors between a household and the infrastructure facilities that provide the resources. These past works have not focused specifically on complex interdependencies of multiple infrastructure systems, and this report's authors suggested that population reaction to cascading failures be modeled in an equilibrium problem by considering spatial distributions of facilities and population.

\subsection{Study approach}

A mathematical framework in the form of a network interdependency model was developed to systematically quantify the effects of cascading failure in a system of infrastructure network systems. The initial approach was developed using the city of Maiduguri, Nigeria, as a case study. Using a combination of existing data and an understanding of how different infrastructure components are used in this location, a geospatially-referenced network model of the critical infrastructures in the city was developed first. Subsequently, cascading infrastructure failures were propagated under different scenarios throughout the network and output geospatially-referenced before-and-after costs to access resources. The results of different failure scenarios were then assessed and several types of sensitivity analysis were performed to better understand both system and model behavior.

\subsection{Study location}

Maiduguri is the capital city of Borno State in northeastern Nigeria $\left(11^{\circ} 51^{\prime} \mathrm{N}, 13^{\circ} \mathrm{O} 5^{\prime} \mathrm{E}\right)$, with an estimated total population of 1.2 million. Concurrent with rapid urban growth, the local government has been facing additional severe challenges. First, the natural hazards such as drought and floods cause significant adverse effects (Odihi 1996). Next, both active military events and terrorist attacks threaten people's daily life and the security of urban infrastructure (Ibeh 2015). In addition, large numbers of internally displaced persons (IDPs) flee into Maiduguri after terrorist attacks, which exhaust the resources in the city, resulting in further pressure on the system (Haruna 2015). From this angle, the model aims to better understand and interpret these pressing social concerns, providing possible policy insights into how best to protect crucial infrastructures, reserve emergency supplies, and avoid humanitarian disasters. 


\section{Methods}

\subsection{Model framework}

As disruption takes place in an infrastructure system, cascading failure begins to develop by following certain failure propagation patterns that are inherent in the network, and people start to change the way they access resources. Eventually, the disrupted system arrives at a state where the remaining infrastructures and the impacted population behaviors fall into new equilibria. Modeling and querying the structure of these new equilibria aims to understand and visualize how local populations might be affected by particular infrastructure changes.

The framework therefore (a) generalizes various types of interdependencies among infrastructures with a layered network model, (b) estimates entangled system failure and equilibrium community behavior as part of a game-theoretical model, and (c) evaluates the cascading propagation of disruptions (due to interdependencies) and the consequential societal impacts (such as demand loss and cost increase). A heuristic algorithm is developed to calculate the system equilibrium. Numerical comparisons based on real-world data are performed to examine the impact of infrastructure cascading failures on the population, and model sensitivities are explored.

\subsection{Network development}

\subsubsection{Nodes}

A 2-dimensional geographic region $\Omega$, such as a small country or a city, was the focus. Within this region, the infrastructure system is characterized by a grand network that contains multiple layers. Each of these layers represents a basic type of infrastructure (e.g., water, food, electricity, fuel, transportation, healthcare, and education). It was assumed that each layer consists of a finite number of infrastructure nodes as the functional units, with specific geographic locations and associated attributes for those nodes. For example, a binary "status" attribute at each node describes whether the component is currently functional or not. Other attributes can be included as necessary to further identify and characterize relevant features of each node, including the nature of the links or edges that connect the node to other components within the system. 
Figure 1 shows four example infrastructure sectors: fuel, power, water, and transportation. These sectors serve primarily as conceptual boundaries that help analysts define the scope of the model as relevant to a particular analysis. The sectors are not fixed or hard-coded, and the model is transferable to locations that may have different types of infrastructure systems. In addition, each sector can be expanded by subdividing it; for example the transportation sector could be separated further into air, sea, and land systems. Each sector is composed of a set of geographically-referenced nodes representing system components. In this example, a water node might be a water tank, a fuel node might be a gas station, and a transportation node might be a road segment. In addition to the four layers just described, a community layer was added to reflect the population distribution, where a node represents a functional unit appropriate to the scale of the analysis such as a neighborhood, household, or commercial entity. Each of the community nodes can be served by components from the infrastructure layers.

Figure 1. Example of linked infrastructure nodes, by sector, with community end-users.

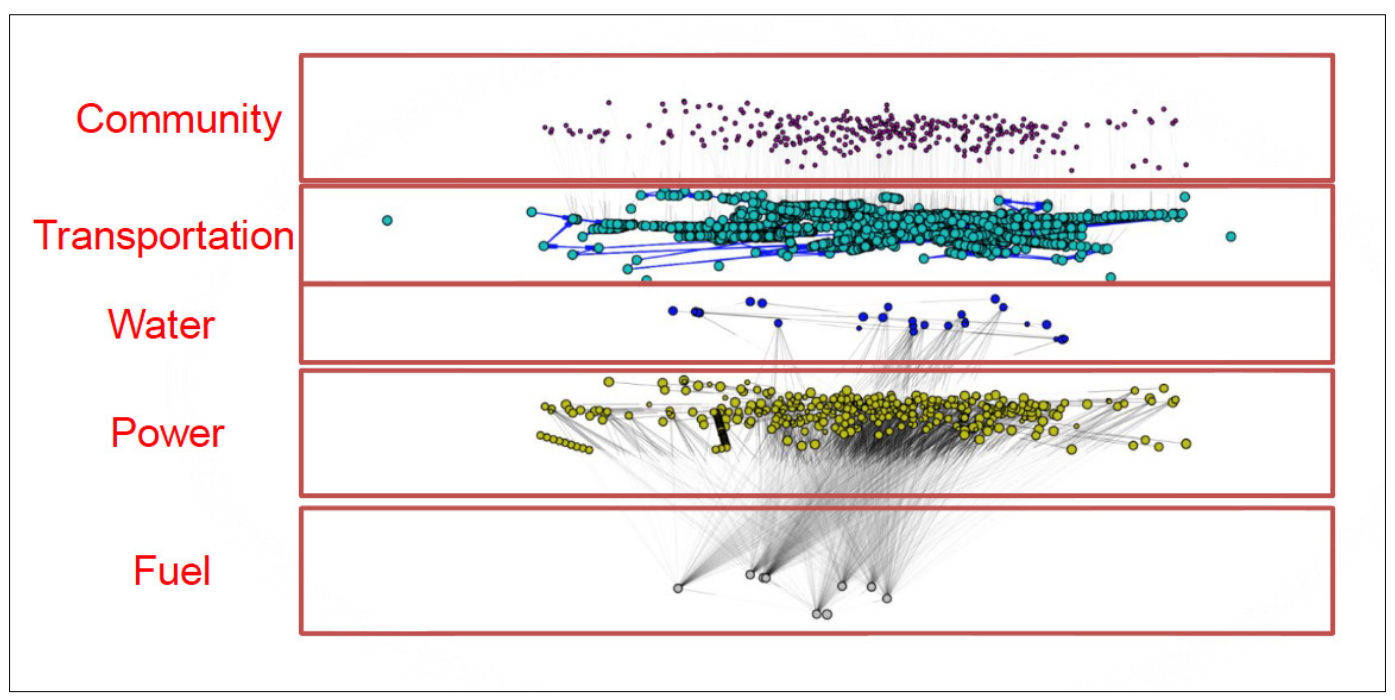

Sectors such as food, water, fuel, healthcare, and education will typically directly provide necessary resources to the community layer, hence are referred to as resource layers. Fuel, electricity, and transportation layers typically serve as the backbone that supports the operation of resource layers in addition to directly supporting community nodes. A generic node in the entire network is denoted by $i \in I$. Further, let $r \in R$ be a resource type (e.g., water, electricity, food, healthcare) and $I_{r} \subseteq I$ be the corresponding 
set of type-r resource nodes; similarly, let $I_{t}, I_{c} \subseteq I$ be the sets of transportation and community nodes, respectively.

\subsubsection{Links}

After the major functional components of the infrastructure and community systems have been defined, links can then be established between components, either within-sector or across sectors as well as to communities. In order to account for both direct infrastructure interdependencies as well as system feedbacks induced by changes in community behavior, the model currently employs two different types of linking mechanisms representing "strong" and "weak" support (Figure 2). These two support types then determine the mechanisms used for failure propagation in the models, described in later sections.

Figure 2. Left: In strong support, if one of the three required inputs to the top infrastructure component fails, then that results in the failure of the downstream component itself. Right: In weak support, the failure of one resource simply means that the downstream component can choose from among alternative sources, and that the downstream component will only fail if the access costs for all available sources are higher than some predefined threshold.

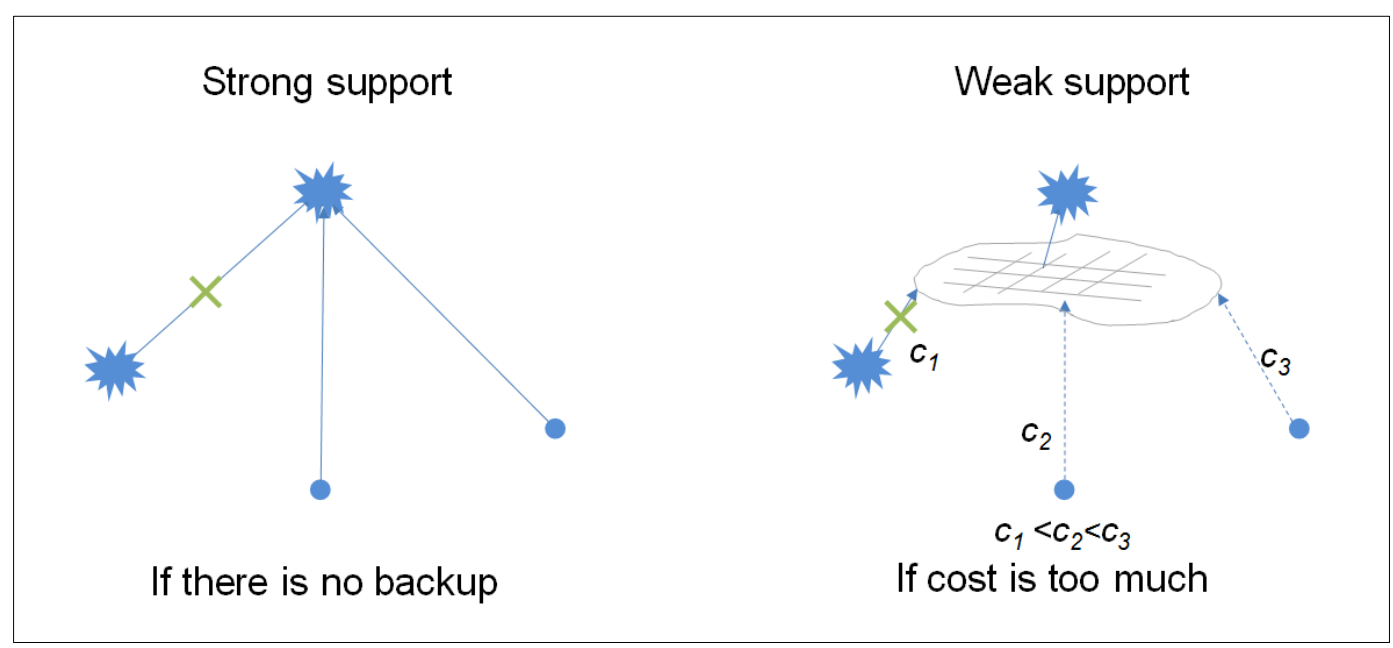

\subsubsection{1 “Strong” support}

Where the functionality of a "downstream" node has a direct dependence on an "upstream" component, this is represented in the network model as "strong support," whereby if an upstream resource fails, the failure cascades to the node that depends on that resource. There currently is no distinction between functional support failure (e.g., a pump cannot move water because the power it requires to run has failed) and input/output 
disruption (e.g., a pump cannot move water because there is no water to move even though the pump itself is functional). In these cases, the failure of either the incoming power or water would similarly trigger the failure of the downstream pump. Typically, strong support is modeled where there are direct physical linkages between infrastructure components that necessarily "push" the cascading failures downstream.

\subsubsection{2 “Weak” support}

Wherever downstream users can access alternative locations of a resource via the transportation network, this is typically represented in the network model as "weak support." For example, if a water pump has failed in one location, a user can access another water location that is perhaps farther away but still relatively convenient, as long as the user is able to transport the water to the location where it is required. In weak support, downstream consumers access the upstream resource based on a user equilibrium cost calculation over the existing transportation network. However, it is noted that this user equilibrium technique is not restricted to transportation network analysis, and can represent any situation where resources are accessed via some network capable of representing those costs. Typically, weak support is modeled where the downstream user has some type of choice between alternative providers of a resource and can "pull" the resource from the most cost-effective site.

\subsection{Data sources}

This section and its subsections document the types and characteristics of the datasets on which the human-infrastructure network model for the Maiduguri case study was based. The mathematical network dependency model with the solution techniques described in subsequent sections is general and theoretically applicable to any location and infrastructure network. However, any given realization of the model will rely on specific data sources to represent the reality on the ground, and the utility of the model will depend in part on how well those human-infrastructure networks are represented. Given that the modeling tool is being designed to be applicable to areas of the world for which data may be sparse or inaccessible, in comparison to infrastructure datasets available for the United States, it may be necessary to first develop the input datasets from imagery and insitu information sources in an area of interest prior to model formulation. In future work, it will also be necessary to develop methods to determine 
the conditions under which model users can have confidence that the input data available to them is adequate for the analysis of a given situation.

\subsubsection{Urban Tactical Planner}

One source for geospatial data on infrastructure in urban areas outside the United States is the Urban Tactical Planner (UTP) product (U.S. Army Corps of Engineers 2015). This dataset provides key aspects of selected urban environments, including built-up terrain zones, buildings of interest, roads and other infrastructure, natural features, and vertical obstructions. The primary source of information for developing the UTP product is aerial imagery, with analysts developing several vector and raster geographic information system (GIS) themes from the image base and other sources. In addition to roads and hydrography, a few vector files typically included in UTP which may be unique to the UTP product and particularly useful to HISA analysis include Key Features, Buildings of Interest, Vertical Obstructions, and Built-Up Terrain Zones (BTZs). Each of these layers is described in more detail below. In addition to these vector layers, three raster layers are included in every UTP product: a Base Image, a Base Map, and an Elevation Layer. For some locations, the UTP product may also contain layers that identify where different ethnic, religious, or political groups reside (if such information is available).

Since UTP products are developed by the U.S. Army Geospatial Center to support military operations in urban terrain, UTP products only exist for select urban areas where existing or potential conflict, peace-keeping, or humanitarian missions are active or anticipated from the perspective of the United States Department of Defense (DoD). Therefore, an UTP product does not exist for all urban areas. The UTP data, as per requirements of this project, is UNCLASS/For Official Use Only (FOUO), with access restricted to DOD common access card (CAC) users.

Key Features is a point feature class identifying the location of cultural features (e.g., houses of worship) or operationally significant features (e.g., police/government buildings). Of particular note, the Key Features layer is one of the major sources of information in the UTP, describing buildings and facilities that are protected under the laws of war (U.S. Army Corps of Engineers 2013).

Similarly, Buildings of Interest is a polygon layer that shows the ground footprint of buildings deemed by an analyst to be of particular importance. 
Similar to the Key Features point layer (and often representing the same structures), the Buildings of Interest layer delineates high-profile cultural features, government and religious buildings, and all types of structures protected under the laws of war (U.S. Army Corps of Engineers 2013).

Vertical Obstruction information consists of vector feature classes (points and lines), originally of primary interest to pilots for the purpose of avoiding structures that could impede safe takeoffs and landings. These features typically include infrastructure components such as radio towers, water towers, and power lines; therefore the layer may be of interest for HISA analysis. These layers aim to include all point structures $>15 \mathrm{~m}$ in height.

Built-up Terrain Zones are delineated by using a method of grouping urban terrain according to its use and physical features. BTZs are classified by form, function, and height.

- Form is categorized as Open-Spaced, Detached Closed Space, and Attached.

- Function is classified as Residential, Commercial, Manufacturing, and Industrial or Institutional.

- Height is classified into height ranges of 1-2 stories, 3-4 stories, 5-15 stories, and $>15$ stories.

For analysis here, the function of BTZs is of particular interest. The residential function type includes single-family homes and apartment complexes along with temporary housing such as campgrounds and refugee camps. In some cases, the residential areas are labeled according to socioeconomic status, such as middle income, poor income, or shantytowns. This income classification is based upon a generalized standard of income on a country-by country basis. The Commercial function type identifies areas that are primarily used for economic activities, such as shopping areas, markets, office complexes, and recreational facilities. It also includes large transportation complexes and areas of mixed use (e.g. first-floor commercial with apartments above). Manufacturing and Industrial function types include large factories and warehouses. Institutional areas are used primarily for government, religious or military functions.

\subsubsection{Open Street Map}

One open source for global, general, background geospatial data, including streets and oftentimes hydrography, electrical lines, and railroads, is 
OpenStreetMap (OSM) (www.openstreetmap.org). OSM is an initiative to create and provide free global geographic data. Because OSM is community driven or crowd-sourced, it is considered a non-authoritative source for geospatial data. However, many of its community members and contributors are GIS professionals, and in some situations the geospatial data content may represent best-available data.

\subsection{Conceptual model construction}

This section describes a conceptual model of the infrastructure-community system in Maiduguri in which the team's goal was to find a balance among an accurate depiction of reality, best use of available data, and inference of additional details that could, in an operational situation, be more robustly supported by additional in situ information. Figure 3 shows the conceptual model of the infrastructure network that was used in the subsequent network equilibrium analysis in Maiduguri. The subsections below describe the reasoning behind the setup of the various sectors, as well as highlighting some of the limitations that model users will need to consider when working with analyses derived from this model. In the HISA workflow, the conceptual model serves to:

- organize analyst understanding of the infrastructure system,

- guide the process of linking geospatial data into a properly constructed network amenable to analysis,

- provide a reference to aid in the interpretation of model results, and

- provide a record of how the analysts' understandings of the network evolved over time as revisions were made and new information was incorporated.

The conceptual model also suggests what could, in the future, be developed into a graphical user interface (GUI) whereby the creation of the mathematical inputs to the network model could proceed directly via user interaction with graphical components.

While based in reality as per the data sources described above and external research, to a large extent the conceptual model elaborated for Maiduguri is a simulated dataset that shares many of the general characteristics of known infrastructure in this location. However, where "proxy" infrastructure components are identified, this means that the actual locations are not known and simplifications have been made to arrive at this particular component configuration. Each sector is documented below, first with a 
general background of the infrastructure sector followed by a summary of how the available information was used to create the conceptual model.

In the conceptual model created of Maiduguri's infrastructure, six utility sectors are represented (Fresh Water, Fuel, Electricity, Transportation, Food, and Community), as well as two institutional sectors (Schools and Medical Facilities) that are treated as infrastructure components rather than community end-users (Figure 3). The sectors in the figure are colorcoded, and component classes within each sector are represented by colored boxes. These boxes are then interconnected either via strong support (e.g., "physical links," with solid black lines) or weak support (e.g., "transportation links," with dashed black lines) to other component classes. Two end-user communities and the links connecting them to the infrastructure network are also represented in this diagram; other end users were represented when the network was encoded, but they are not represented here. Components that are semitransparent also have not yet been included in the model. The additional text below each component box details some of the attributes that characterize the linkage types for each component. The following section describes the location-specific model representations and assumptions for each infrastructure sector represented in this diagram. 
Figure 3. The conceptual infrastructure network model for Maiduguri. Colored boxes represent types of nodes in the network; solid black lines and arrows indicate strong support; dashed black lines indicate weak support. Semi-transparent nodes have not yet been represented in the model (ERDC-CERL).

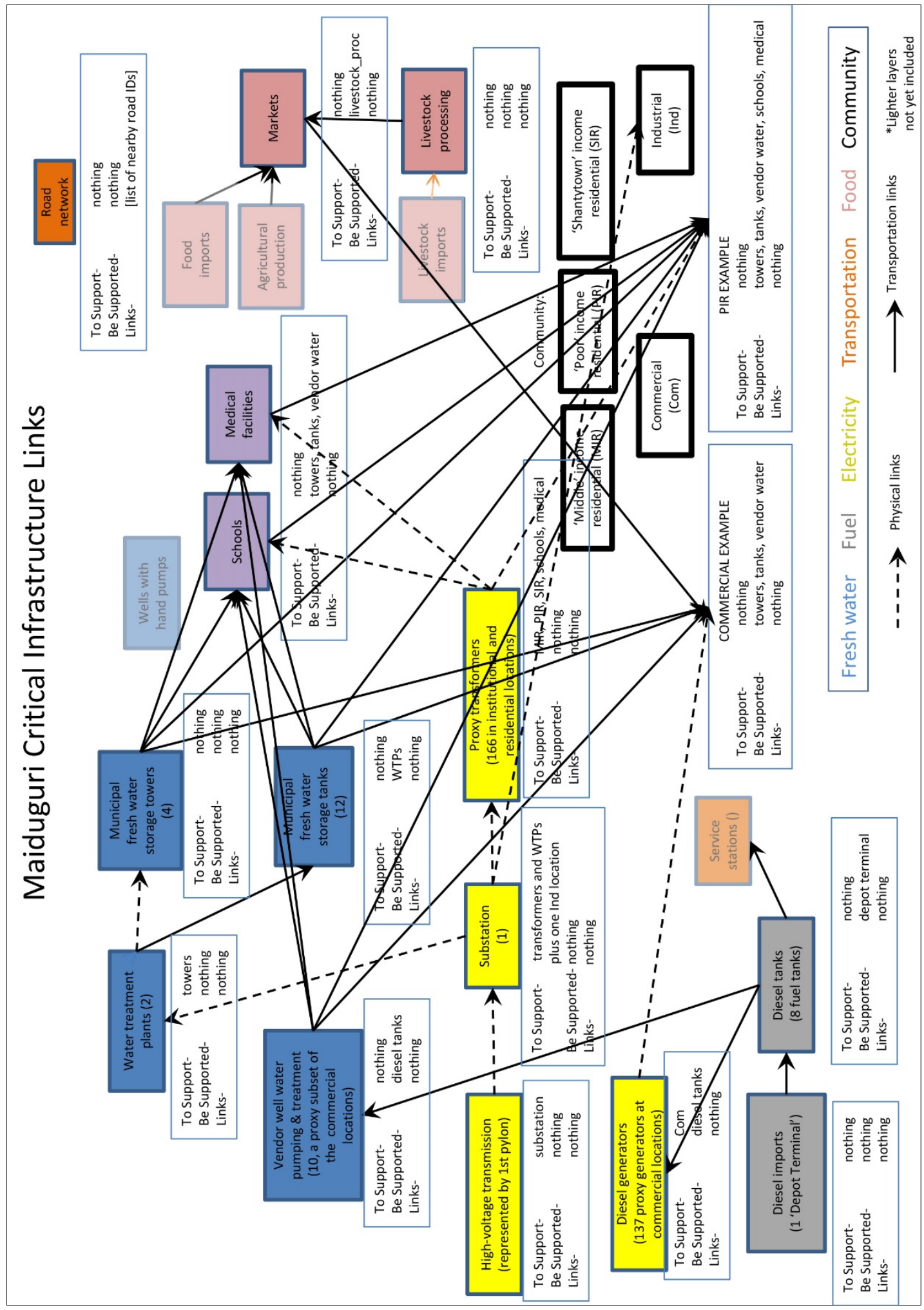




\subsubsection{Fuel sector}

\subsubsection{Background}

There is one location in Maiduguri, termed the "depot terminal," where diesel fuel is delivered via pipeline to the outskirts of the city. The source of this diesel is refineries in the southwestern part of the country. A network of both formal and informal fuel distribution stations exists within the city to distribute this resource, many of which may be co-located with service stations identified in the UTP. Recent news reports indicate that Boko Haram insurgents operating in Maiduguri have created their own locations at which fuel is stockpiled for their own use (Sahara Reporters 2015). This demonstrates the dynamic nature of infrastructure systems in conflict zones and underscores the importance of understanding and monitoring both formal and informal infrastructure networks in urban areas where hostile and friendly forces exist in close proximity.

\subsubsection{Conceptual model}

The conceptual model begins with the inclusion of the depot terminal. Components of the fuel sector external to the city itself are not modeled, and it is assumed that if the depot terminal is operational, then diesel fuel is accessible. A subset of eight locations of otherwise unspecified types of "tanks" in the UTP that were located near roads were selected as representative locations for fuel storage and distribution in the city. This first iteration has not integrated service stations into this network of possible distribution stations.

The UTP does not include information on the layout of any underground fuel pipelines within the city, and the link between the depot terminal and the diesel tanks has been modeled as a transportation link, presuming that this transfer typically takes place via tanker trucks. It is important to note that, currently, the model does not track actual volumetric flow or storage of the fuel itself, nor volume for water or any other resource. Because each diesel tank relies on the depot terminal, a disruption of the single "depot terminal" means there is no secondary location from which the tanks might pull fuel. In this case therefore, an immediate disruption of the fuel supply at the diesel tanks would occur, irrespective of how much fuel might be stored in the tank or the rate at which it may be depleted. Diesel is itself a resource used by all the vehicles in the transportation system. However, this dependence is not explicitly modeled at this time; rather, all 
fuel is passed via weak linkages from the 8 fuel tanks to the set of 137 proxy diesel generators placed in commercial locations throughout the city.

\subsubsection{Electricity sector}

\subsubsection{Background}

Electrical generation occurs in the southern part of the country and is transmitted long distances via 330 or $132 \mathrm{kV}$ transmission lines, periodically boosted at transmission stations. Delivery currently comes from one transmission line that goes through the town of Damboa to the south, although there are plans for an additional transmission line to connect from the west to make the system more resilient. Electricity provision typically does not keep up with demand, and outages, both forced and planned, are common nationwide throughout the network. Electrical infrastructure has also been a target of vandalism and concerted attacks. In June 2014, the 330/132 kV substation in Damboa was set on fire, and in mid-July 2014, a conductor on a transmission line was cut somewhere between Damboa and Maiduguri, resulting in a complete electrical blackout for Maiduguri. The blackout lasted almost three months; finally, with the help of federal forces for security and logistics, the transmission company was finally able to restore power. Distribution is managed at the local level, wherein Maiduguri is one of four districts belonging to the Yola Electricity Distribution Company. After various privatization initiatives across Nigeria, Yola now has a technical partner in the Philippines-based MERALCO. Yola owns a total of 124 circuits and related substations ( 33 and $11 \mathrm{kV}$ ) and close to 1 ,ooo smaller distribution substations. The UTP identifies a set of pylons that bring electricity from the high-voltage country-level transmission network to the two nearly co-located electrical substations in the center of Maiduguri as well as a dual substation also located in the center of the city. Sources do exist with names and/or descriptions of electricity service zones (e.g., Waziri 2009), but the information is not currently available in formats amenable to geospatial analysis.

Several internet-based news articles provided some indication of the effects of the summer blackout of 2014 as well as other infrastructure attacks, many of which have been incurred by the insurgent group Boko Haram. 
Boko Haram has, in the past three years, vandalized public infrastructure like telecommunication masts that had hitherto cut off various parts of Borno State from the rest of the world. The group had also used bombs and fire to destroy schools, hospitals, police offices, barracks and even cratering of roads. Their most recent attack on public infrastructure was the bombing of an ultra-modern drilling rig procured by Borno State at the cost of over N300 million at the site where it was mobilized to drill water for rural dwellers of the northern part of Borno State. (Boko Haram Attacks Power Station 2014)

Simply due to the extended length of the Maiduguri blackout, it is likely that private operators of water pumps now have gained gas-powered generator access, and for this reason, interdependency between the electrical and water systems may be quite weak compared to that of "more-developed" locations. However, another researcher notes that running small businesses on generators is typically prohibitively expensive and that the lack of electricity at night "creates a cover for insurgents to operate" (Murdock 2014). One article also highlighted the effects of the blackouts on subpopulations that the model does not explicitly delineate: "Cold chain stores for fruits and vegetables preservation will come to a halt, with increasing losses of goods and sales revenues of marketers and traders, including the over 15,000 butchers and Maiduguri Monday Market traders that solely rely on trading to survive and send their children to school," and that "the economic situation of vulcanisers and welders that constitutes about 45 per cent of labor force will be made worse" (Olugbode 2014).

\subsubsection{Conceptual model}

The conceptual model includes: (a) one of the pylons representing the electricity provided by the national network, (b) one substation to represent the two nearly co-located nodes in the UTP, and (c) a set of 166 "proxy transformers" throughout the city in institutional and residential community locations to represent likely community links to the power grid. The proxy transformers are also connected to schools and medical facilities via "strong support" links. In the conceptual model, the water treatment plants and a small number of industrial locations are also provided power via the substation directly. 
In addition to the fixed electrical infrastructure network that is notoriously unreliable, many commercial enterprises employ diesel-powered generators for their businesses. The conceptual model represents this by placing a generator at each of 137 commercial locations identified by the UTP across the city, each of which can "pull" diesel fuel from one of the 8 diesel tanks via a weak support link.

\subsubsection{Water sector}

\subsubsection{Background}

Before 1985, urban access to water in Maiduguri was via 65 deep boreholes with pumps; however, two severe droughts in the 1970s brought rural residents to makeshift urban settlements and urban groundwater levels declined up to $7 \mathrm{~m}$ between 1975 and 1980 (World Bank 1996). This prompted the World Bank to fund a project costing \$72 million in U.S. dollars (USD) from 1985 to 1995 for water pumping and treatment from Lake Alau, Nigeria, located southeast of Maiduguri. A water-sharing agreement specified that during normal years, the water was to be shared equally between urban and irrigation uses, and during drought years, priority would be given to urban use. The project included a treatment plant, pumping and storage facilities, and transmission and distribution lines.

Despite completion of a substantial portion of the planned infrastructure improvements, at project closeout the World Bank judged the outcome to be unsuccessful for a variety of reasons (World Bank 1996). These reasons included use of sensitive equipment ill-adapted for windy and hot atmospheric conditions, and possibly seasonally-variable raw water quality conditions; failure to establish a reliable supply chain for obtaining replacement parts and chemicals required for operation; failure to procure resources to purchase fuel, spare parts, and chemicals; lack of monitoring and control of the water distribution network with failure to address illegal connections; unsustainable costs for customers (e.g. sustainable rates to cover utility costs would have required charging 30\% of an average civil servant's salary); failure to train management and/or consider difficulties of working with the underperforming civil service sector; and "too much reliance on external technical assistance to perform key functions of project implementation" (World Bank 1996) Even during the project, onethird of boreholes were inoperative due to lack of maintenance and only one of four valves at treatment plant was operable at time of project closeout. The World Bank closeout report states that 
...the key lesson doubtless remains that it does not suffice to construct physical facilities for provision of water; of equal importance - if not more so - is to develop the institutional capacity of the water utility and to provide it with the necessary independence to successfully operate and maintain physical installations. For if such capacity does not exist, as is the case with the Bomo State Water Corporation, expensive installations will rapidly deteriorate and customers will become disillusioned. Allied to this, is the need for the institution to be able to develop a realistic policy for connection of consumers to the system, and a charging policy, in order to enhance revenue, serve the maximum number of people, and maintain affordability... There is little question that the majority of people are willing to pay for safe, reliable drinking water, however their ability to do so will depend on macro-economic conditions unrelated to the project. [Another] key lesson is that macro-economic conditions can deteriorate rapidly through earlier unforeseen circumstances, jeopardizing the sustainability of a project.

In addition, a flood that occurred in 1994 destroyed some of the infrastructure, handicapping the ability of the utility to provide (and demand payment for) consistent services during that year.

According to the 2010 census data (Minnesota Population Center 2015), which included only very limited sampling of urban areas in this part of the country, no urban residents in the state of Borno had piped water and $100 \%$ of the water supply was provided from surface water. This might indicate that even where the water is supplied by a system of tanks and pipes from a water treatment plant, it is distributed at the neighborhood level via trucks or hand carrying. In recent years, businesses that pump, treat, and package groundwater for household use have become commonplace. This water, also known as "sachet water" (Figure 4) has become an important resource for urban household use in Nigeria. (Dada 2009). 
Figure 4. Example package of sachet water

(https://udeozochibuzo.wordpress.com/2014/01/14/cash-spiner-

polyethylene-or-sachets-printing-business/).

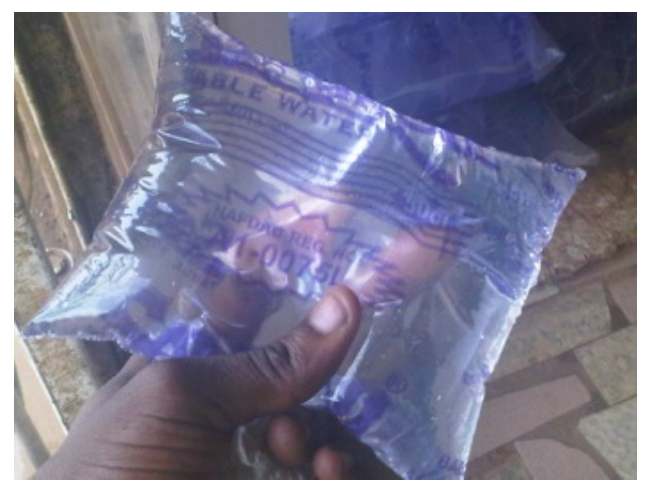

\subsubsection{Conceptual model}

Despite the negative World Bank assessment of the state of water treatment facilities, the UTP indicates the water treatment is at least marginally functional. It also identifies a water treatment plant near the airport, four water towers, and six reservoirs. Of the UTP tanks of undefined function, 12 tanks (or sets of tanks) were selected for the model as proxy water tanks based on one or more of the following criteria: nearby building function, location in higher elevations, proximity to a reservoir, and distance from main roads. There is one known pumphouse near the airport that presumably is associated with the water treatment plant and fills the nearby tanks from the reservoir. The facility was presumed to treat water for drinking and not wastewater, given that the census indicates that latrines are the norm for urban areas in Borno state. It was also presumed that any reservoirs hold untreated water and thus are not represented in the urban water infrastructure sector modeling.

The conceptual model has been populated with the two water treatment plants which rely on electricity from the substations. These treatment plants feed a set of four municipal fresh water storage towers via a strong, presumably piped link; they also feed 12 proxy municipal water storage tanks via a weak, presumably truck-delivered link. These tanks and towers in turn supply schools, medical facilities, residential areas, and commercial areas with water via weak links. To represent the "sachet water" component, a set of 10 proxy vendor-operated well water locations was located at a subset of commercial locations near surface water or otherwise in locations that might be amenable to groundwater pumping. These businesses rely on electricity provided by their own or privately owned diesel generators. 


\subsubsection{Food sector}

\subsubsection{Background}

The state of Borno has traditionally been a gateway for trade in agricultural products, livestock, and textiles between northern Nigeria and neighboring countries including Cameroon, Chad Niger, and the Central African Republic. In recent years, Boko Haram fighters in the area have blocked highways, destroyed infrastructure, and killed drivers. This mayhem is severely dampening commerce and preventing agriculturalists living in villages and cities from accessing their lands to plant. In March 2014, there were an estimated 250,000 internally displaced persons in the three northeastern states of the country including Borno, largely due to the activities of the insurgent group (Ahmed and Eckel 2014).

Many urban residents of Maiduguri own farms outside the urban area and commute from the city to the farms for planting and harvesting and then bringing the harvests back to the city for sale in markets. Livestock from northern pastoral areas of the country also are delivered to the city, which has a cluster of animal markets and processing facilities along the northeastern route into the city. Urban markets have been a major target of insurgent suicide attacks in recent years.

Given the irrigated areas outside of the city (Figure 5) as well as the prevalence of boreholes in rural areas, the water sector is known to be intimately tied to the agricultural sector of the economy. However, this analysis focuses only on water provision for household and commercial use within the urban area and does not explicitly link the water sector to the food sector in the infrastructure model. 
Figure 5. Imagery shows the agricultural area northeast of Maiduguri's urban area during April 2014 (top) and November 2013 (bottom). Fields and orchards that are green during the dry season have year-round access to irrigation, either via wells or via surface water.

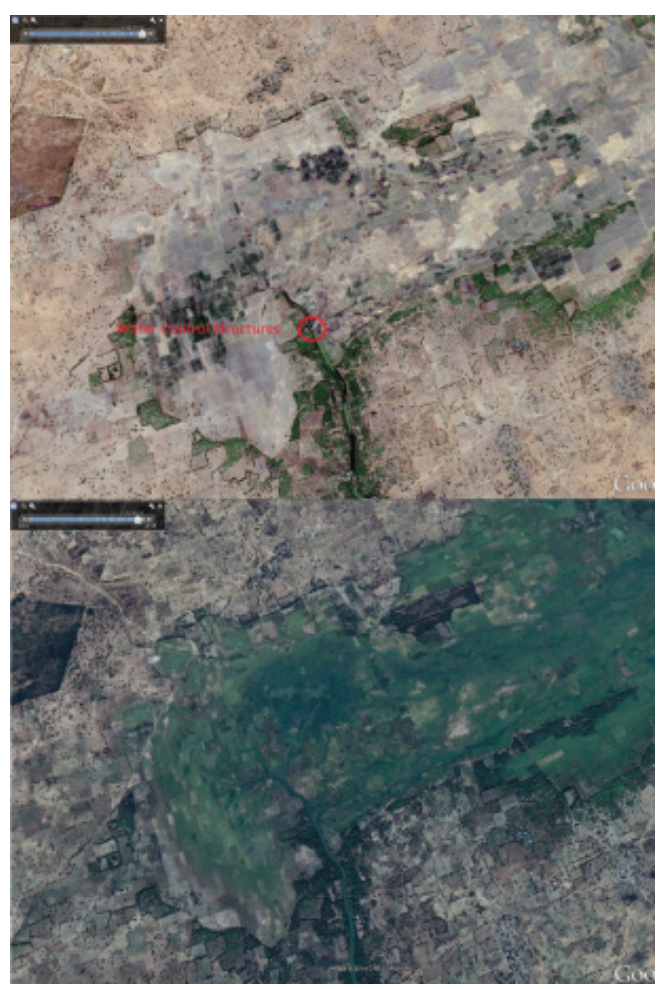

\subsubsection{Conceptual model}

In the current conceptual model, the food sector is only minimally represented with three livestock processing facilities that are weakly linked to eight major market locations across the city. In turn, these market locations support residential and commercial community users via weak links.

\subsubsection{Community sector}

\subsubsection{Background}

Population estimates for the city of Maiduguri vary widely; a 2011 estimate based on 2006 census figures and enumeration areas demarcated by the National Population Commission bracketed the population of the combined Maiduguri and Jere local government areas between approximately 1 and 2.7 million people (Waziri 2009). Since that enumeration, however, an estimated 250,000 Nigerians have been forced to flee their homes in northeastern states in response to threats and attacks associated with 
Boko Haram. Many of these IDPs have fled to major urban areas like Maiduguri, so the current population is likely to be much higher than estimates made in the previous decade.

Higher population density occurs in several districts: Gwange, Shehuri North, Old Maiduguri, and Yerwa, each of which has over 10,000 people per square kilometer. The Ministry of Land and Survey has categorized housing density into high-, medium-, and low-density areas based on plot sizes, although this information is not always well correlated with the number of households living on a particular plot. The number of houses in a given administrative ward has been counted in a 2011 polio eradication program, and independent researchers have also counted individual houses per unit area in select wards of the city (Waziri 2009).

The northern regions in Nigeria are populated by mainly Muslim ethnic groups such as the Hausa, Fulani, and Kanuri, whereas populations in the south of the country are largely Christian Yoruba and Igbo (Ahmed and Eckel 2014). Maiduguri is majority Muslim, but as a state capital and university town also is has some Christian presence; the UTP Key Features layer identifies over 90 mosques and fewer than 10 churches. In the model prepared for this work, however, there is no differentiation between communities based on any presumed ethnic or religious identities.

\subsubsection{Conceptual model}

In the model, rather than compiling information from the various sources listed above, the BTZ layer of the UTP was used. These BTZs delineate sets of polygons associated with different land use and residential income characteristics. There are 92 middle-income residential, 30 poor residential, 2 shantytown residential, 137 commercial, 5 industrial, and 42 institutional polygons. Together these polygons cover a substantial majority of the urban area.

The population of each community polygon was estimated by using the LandScan $^{\mathrm{TM}} 2010$ dataset created by Oak Ridge National Laboratory (ORNL 2010). To produce the estimate, the LandScan raster was converted to a polygon layer, then intersected it with each of the BTZ layers, and multiplied it by the fractional area of each community within that LandScan grid cell. By summing this value over all LandScan cells in a given community polygon, an estimate was obtained for the populations represented by each community. These community population values can 
be used in the network equilibrium model for calculations of demand and queuing time. As an alternative, another simpler representation of population can be used whereby fixed numbers are assigned to communities by community type, with the mixed commercial-residential areas found near the center of the city having the highest populations and areas more commonly found further from the city center are assigned lower values.

The BTZ Institutional community layer was not used directly in this analysis. Institutions in this layer included police, court, and military facilities as well as universities, but the type of access cost changes modeled with network equilibrium techniques does not transfer easily to the types of resources and services supplied by these institutions; a community near a military base is not necessarily better positioned to have better "access" to military-derived resources. Institutions like the military and the police which "go out" into the communities in very directed ways could potentially be modeled in this system, but would require a third type of linkage that is different from both the strong and weak supports currently being used for other resource types. This third type of linkage would itself require very specific information as to the communities targeted for specific operations, as well as some way to quantify the value of the provided resources. This type of model development is beyond the scope of the current project, however, which aims to assess the effects of physical infrastructure changes on local populations.

Therefore, the representative institutions chosen were the 84 schools and 4 hospitals or medical facilities identified in the Key Features layer, which were then treated as separate infrastructure components that served the residential populations. Currently, this model does not distinguish between types of hospitals or levels of schools, but such a distinction could be included in future analyses. Of primary importance for the community layers is defining from which infrastructure resources they pull via weak links to the system. In this case study, all types of communities needed to access water, food, education, and medical resources, with the exception of the few industrial locations for which only water demand was represented (in the absence of more specific information on the industrial needs at these locations). 


\subsubsection{Transportation sector}

\subsubsection{Background}

Residents of and travelers to Maiduguri use a wide variety of transport options from cars, trucks, and buses to motorbikes and bicycles, to donkeys and camels, and to pedestrian transport. The city also has an airport with flights connecting to a few major Nigerian cities. Motorbikes in particular have become common and in some cases, they dominant in congested urban areas in Nigeria, particularly for lower- and middle-class residents.

In Maiduguri, the transportation network and options have at times been significantly affected by the Boko Haram insurgency and the military responses to it. On at least two occasions, the government instituted a temporary ban on motorbikes, apparently with varying levels of success, to address violent attacks by gunmen from that particular transportation platform ("City-Wide Motor Bike Ban" 2011). On certain other occasions such as Eid al-Adha observance in 2015, the government has gone so far as to ban all cars, public transport, horses, donkeys, and camels in the entire state for the duration of the holiday. Vehicular transit in and out of the city at other times has also been restricted ("Nigeria's Boko Haram Crisis" 2015). These events highlight the notion that in a city like Maiduguri, where the population relies heavily on "weak support" via the transportation network for many aspects of resource acquisition, it may be important for the infrastructure model to have the capability to represent a transportation network that is dynamic both in its physical structure and in the cost values assigned to traversing each node.

\subsubsection{Conceptual model}

To represent the transportation network in the conceptual model, an ESRI $^{*}$ multipoint dataset including over 9,500 road segments was derived from OSM data. Road types represented in the dataset included primary, secondary, tertiary, residential, and trunk segments. Residential segments were removed in order to build the road network on only major roads. Some apparent gaps that led to incorrect dead-ends in the resulting network were cleaned up manually, and the resulting nodes were linked together in a simplified network that attached each node to the four closest nodes within a threshold distance of 0.02 degrees, thus making it possible

\footnotetext{
* ESRI develops and markets software that melds maps with data for expert analysis.
} 
to represent intersections. This simplified road network was developed primarily with a goal of fast processing time; in a full model run, it would be desirable to use a full road network with appropriate network cost values on each road segment according to the different road types, typical transit speeds, or potentially user-dependent transit speeds.

\subsection{Translation of conceptual model to network model input}

After the conceptual model was defined, it was translated (encoded) into appropriate input for the network equilibrium analysis. First, the relevant point data was created and loaded into an ESRI geodatabase with feature datasets representing the infrastructure sectors and point feature classes representing infrastructure components within each sector. Then, for each component node, a unique node identification number was assigned that encodes the sector and component type as well as an individual component number. This unique and succinct identification number can then be used both by humans and automated systems to understand and/or process the network information. For each node, an attribute was created to describe operational status (a binary value indicating whether or not the node is functional). Next, the strong and weak network linkages between nodes were defined as follows: for direct support, nodes that the current node directly pushes resources to in the form of strong support are enumerated; for weak support, nodes that the current node can receive resources from are enumerated. An additional attribute is then added for the transport layer to represent the transport nodes directly connected to the current node. In this process, the conceptual model is used as a reference to develop and document the code that populates the geodatabase with the desired attributes that define the network. When the process is complete, information on all nodes in the geodatabase is exported and passed to the network model. This dataset includes the geographic location of each point, the node identification numbers, the operational status, and the linkage information. The code that populates the geodatabase serves, therefore, as the final documentation for the network structure.

\subsection{Alpha model development}

This section describes the analysis framework used for the initial Alpha layered network model, addressing mechanisms of community behavior, mechanisms of disruption propagation, representations of system equilibrium, and calculations of social impact measures. The heuristic method used to determine system equilibrium is also explained in this section. 


\subsubsection{Community behavior}

Typically, especially after disasters, people access life-supporting resources by utilizing the transportation layer. The trivial case that people get resources within the community, (e.g., tap water at each household), can be incorporated as traveling a distance of zero. Under disruption, fewer resource nodes remain functioning, which can lead to overwhelming demand concentration and associated long queuing, longer travel detours, and associated traffic congestion. This situation significantly increases people's resource access costs and may further lead to demand loss (i.e., people giving up service) if the costs exceed affordability for a given community. A variant of the traffic equilibrium model was implemented to capture this issue.

Suppose the demand for resource $r$ for each community $i \in I_{c}$ is independent of each other. Demand is denoted by $d_{i}^{r}$, and the corresponding resource access incurs cost $c_{i}^{r}$. Under infrastructure disruptions, the procurement of resources normally becomes more difficult (e.g., obtaining water from a distant tank rather than from a local tap or pipeline in the case of a water network disruption). This will lead to the increase of $c_{i}^{r}$, and hence the decrease of $d_{i}^{r}$, that is,

$$
d_{i}^{r}=D_{i}^{r}\left(c_{i}^{r} ; d_{i}^{r 0}\right),
$$

where:

$$
\begin{aligned}
& D_{i}^{r}(\cdot) \text { is a decreasing inverse demand function capturing the } \\
& \text { elasticity } \\
& d_{i}^{r 0} \text { is the initial demand without infrastructure failures. }
\end{aligned}
$$

In reality, the calculation of $c_{i}^{r}$ is complicated. To this end, the following assumptions are considered:

First, each community $i$ can access resource $r$ at any resource node $j \in I_{r}$ with a resource access cost

$$
c_{i j}:=c_{i j, t}+c_{i j, s},
$$


where:

$c_{i j, t}$ is the travel time along the shortest path from $i$ to $j$ via the transportation layer

$c_{i j, s}$ captures service (queuing) time at $j$

$p \in P_{i j}$ is a path (i.e., $p \subseteq I_{t}$ ) connecting $i$ and $j$ through the

transportation layer and

$g_{k}, k \in I_{t}$ be the demand flow on transportation node $k$.

Then, the result is

$$
c_{i j, t}=\min _{p \in P_{i j}} \sum_{k \in p} T_{k}\left(g_{k}\right)
$$

where:

$$
\begin{aligned}
& T_{k}\left(g_{k}\right)=\delta_{k}\left(1+\alpha_{k}\left(\frac{g_{k}}{\gamma_{k}}\right)^{\beta_{k}}\right) \text { is the conventional Bureau of Public } \\
& \text { Roads (BPR) function (Sheffi 1985), and } \\
& \alpha_{k}, \beta_{k}, \gamma_{k}, \delta_{k} \text { are node-specific parameters. }
\end{aligned}
$$

Furthermore, the resource procurement at node $j$ is considered to line up as an $\mathrm{M} / \mathrm{M} / 1$ queue (other options are discussed in An et al. 2015). Hence, the average waiting time is computed as:

$$
c_{i j, s}=\frac{1}{\lambda_{j}-h_{j}},
$$

where

$$
\begin{aligned}
& \lambda_{j} \text { is the given service capacity and } \\
& h_{j}<\lambda_{j} \text { is the total acceptable demand flow to } j .
\end{aligned}
$$

Second, community $i$ should choose the resource node(s) with the minimum access cost, i.e.:

$$
c_{i}^{r}=\min _{j \in I_{r}} c_{i j}
$$


Given $f_{i j}^{p^{*}}$ as the optimal demand allocation along path $p$ produces the following:

$$
\begin{gathered}
\sum_{j \in I_{r}, p \in P_{i j}} f_{i j}^{p^{*}}=d_{i}^{r}, \forall i \in I, \\
\sum_{i \in I, p \in P_{i j}} f_{i j}^{p^{*}}=h_{j}, \forall j \in I_{r}, \forall r \in R,
\end{gathered}
$$

and

$$
\sum_{i \in I, j \in I_{r}, p \in\left\{P_{i j}, k \in p\right\}} f_{i j}^{p^{*}}=g_{k} \forall k \in I_{t} .
$$

Here, note that the scarcity of each resource is modeled by its access difficulty rather than by the amount procured. That is, the supply at each working resource node is assumed to be unlimited.

Given the seven infrastructure layers, the transportation layer reaches the above equilibrium (i.e., equations (1)-(8)) when no community can reduce its resource access cost by unilaterally changing its resource nodes or the travel path choices.

\subsubsection{Disruption propagation mechanism}

Now, consider the scenario where there are disrupted infrastructures. First, to maintain working status, some infrastructure nodes need resource supply, which are also transported via the transportation layer (e.g., a diesel generator accesses fuel from diesel tanks filled by tanker trucks). Therefore, the traffic congestion under the community behavior may significantly delay or block resource procurement as well, or even cause failure to the infrastructure. This type of failure is referred to as a resource failure.

Second, infrastructure disruption could also be due to direct and obvious dependencies based on physical connections. For example, a water tank with an electrical pump must be supported by a nearby power source (e.g., a power grid). Such a dependency is normally established for the long run, at a large setup cost, and hence difficult to modify. This type of failure, caused by supporting infrastructure disruption, is referred to as support failure. 
Comparing the two types of failure, support failure is found to be one major cause of cascading disruptions. In particular, a network with a very dense presence of links (e.g., a tree) can be very vulnerable-the failure of the root node will propagate (cascade) and disrupt the entire system. In contrast, resource failure normally poses a potential risk, but one that is less obvious to foresee in advance. However, resource failure can also bring devastating damage to the entire system, especially when it happens at some critical node that can cause consequential cascading support failures.

To model infrastructure cascading disruption, let $x_{i} \in\{0,1\}$ be the working status of each node $i$, where $x_{i}=1$ indicates the node is working, or o indicates otherwise. Resource failure is formulated first. Suppose the notations and equilibrium conditions for community behavior also hold for a generic node $i \in I \backslash I_{c}$. Let $\epsilon_{i}^{r}$ be the minimum requirement of resource $r$ to run the infrastructure node $i$. Then, if there exists any $r \in R$ such that $d_{i}^{r}<\epsilon_{i}^{r}$, then a resource failure happens at $i$. As for the support failure, $S_{i} \subseteq I$ is defined to be the subset of nodes that support $i$. That is, there is physical interdependency between each node in $S_{i}$ and $i$ such that if any $i^{\prime} \in S_{i}$ fails, it would lead to the disruption of $i$.

Therefore, the condition for node $i$ to be functioning can be expressed as the following:

$$
x_{i}=\prod_{j \in S_{i}} x_{j} \prod_{r \in R} 1_{d_{i}^{r} \geq \epsilon_{i}^{r}},
$$

where $1_{(\cdot)}$ is the indicator function, taking the value of 1 if the condition (.) holds and o, otherwise. Note that when $\epsilon_{i}^{r}=0$ holds, it implies node $i$ does not need resource $r$. For notation consistency, for community $i \in I_{c}$, set $\epsilon_{i}^{r}=0$ for all $r$ and $S_{i}=\varnothing$, without loss of generality. This notation will guarantee $x_{i}=1$ always holds for a community node; i.e., no community is allowed to disappear.

\subsubsection{System equilibrium}

With the resource equilibrium conditions and the infrastructure disruption mechanism, the system equilibrium is now ready to show. Given the collection of all system parameters as 


$$
\boldsymbol{\theta}:=\left\{\alpha_{k}, \beta_{k}, \gamma_{k}, \delta_{k}, \lambda_{k}, \epsilon_{i}^{r}, D_{i}^{r}, d_{i}^{r 0}\right\}_{k \in I_{t}, i \in I, r \in R},
$$

then

$$
\Gamma(\boldsymbol{\theta}):=\left\{x_{i}, d_{i}^{r}, c_{i}^{r}: \text { s.t. Constraints (1)-(9) }\right\}_{i \in I, r \in R},
$$

defines all system variables that form an equilibrium state. Hence $\mathbf{s} \in \Gamma(\boldsymbol{\theta})$ depicts one of such equilibrium state. Particularly, let $\mathbf{s}^{0}:=\left\{\mathbf{s} \in \Gamma(\boldsymbol{\theta}): x_{i}=1, \forall i \in I\right\}$ be the system equilibrium in the normal scenario.

It can be observed that Constraints (1)-(8) guarantee an unique equilibrium for any given $\left\{x_{i}\right\}$; however, it is possible that there are multiple equilibrium states that have different working infrastructures $\left\{x_{i}\right\}$ and yet satisfy Constraints (1)-(9). Each infrastructure is assumed to remain functioning unless failure is absolutely necessary, and hence only the equilibrium with the most working infrastructures is considered. Then, given initially disrupted infrastructures, $Q \subseteq I$ such that $x_{i}=0, i \in Q$, the system equilibrium after failure propagation is determined by

$$
\mathbf{s}^{Q}:=\underset{\mathbf{s} \in\left\{\Gamma(\boldsymbol{\theta}): x_{i}=0, \forall i \in Q\right\}}{\arg \max } \sum_{i \in I} x_{i}
$$

\subsubsection{Social impact}

This section quantitatively evaluates the social impact of system failure. In general, the social impact is multi-faceted. First, from a societal perspective, the reduction of demand in the served community may reflect the degree of people's unmet needs, suffering, or risk of dying under disruption situations. Second, from an economic perspective, the resource procurement cost significantly increases; meanwhile, the disrupted infrastructure may require significant economic resources and effort in order to recover functionality. To this end, the following three measures are considered as proxies for evaluating social impact across a set of communities for each type of resource: (1) total demand loss, (2) average procurement cost increase, and (3) total infrastructure failure.

Given the initial infrastructure disruption $Q$, the system equilibrium moves from the normal scenario $\mathbf{s}^{0}$ to $\mathbf{s}^{Q}$. Hence, for each resource $r \in R$, the total demand loss is: 


$$
\Delta_{d}^{r}=\sum_{i \in I_{c}}\left(d_{i}^{r 0}-\left.d_{i}^{r}\right|_{\mathbf{s}^{Q}}\right)
$$

the average procurement cost increase:

$$
\bar{\Delta}_{c}^{r}=\frac{1}{\left|I_{c}\right|} \sum_{i \in I_{c}}\left(\left.c_{i}^{r}\right|_{\mathbf{s}^{\underline{Q}}}-\left.c_{i}^{r}\right|_{\mathbf{s}^{0}}\right),
$$

and the total infrastructure failure:

$$
\Delta_{x}^{r}=\sum_{i \in I_{r}}\left(\left.x_{i}\right|_{\mathbf{s}^{0}}-\left.x_{i}\right|_{\mathbf{s}} \mathrm{Q}\right)
$$

More sophisticated impact measures are possible, but they are beyond the scope of this paper and are left for future research.

\subsection{Solution approach}

In this section, a heuristic algorithm is developed that extends the conventional Frank-Wolfe algorithm (Sheffi 1985) to obtain $\mathbf{s}^{Q}$. Noticing the resource demand is elastic and there exists a queuing problem at the resource node, an equivalent problem with constant demand in a new network representation was constructed.

In the new network, a virtual node $i^{r}$ is added for each resource $r \in R$. Then, two types of virtual roads (nodes) are added to the transportation layer to capture demand elasticity and queuing issues, respectively. First, a virtual road $k_{j}$ is added from any $j \in I_{r}$ to $i^{r}$, with

$$
T_{k_{j}}\left(g_{k_{j}}\right)=\frac{1}{x_{j}\left(\lambda_{j}-g_{k_{j}}\right)},
$$

and the original demand flow to $j$ is directed into a new destination $i^{r}$. Hence, $g_{k_{j}}$ exactly takes the value of $h_{j}$, and the queuing cost is converted to an equivalent transportation cost. When $x_{j}=0$, the transportation cost goes to infinity, which guarantees no demand flow goes to $j$. Second, for each $i^{r}, r \in R$, a virtual road $k_{i}^{r}$ is added from any $i \in I$ to $i^{r}$, with 


$$
T_{k_{i}^{r}}\left(g_{k_{i}^{r}}\right)=\tilde{D}_{i}^{r}\left(g_{k_{i}^{r}}\right),
$$

where $\tilde{D}_{i}^{r}$ is the inverse function of $D_{i}^{r}$ as in (1), and fix the resource demand at $i$ to be $d_{i}^{r 0}$.

In so doing, all resource demands at $i$ are constant regardless of the resource procurement cost or working status of infrastructures (overflows or lost demand are "sent" via virtual links). Furthermore, all demand of resource $r$ goes to the same node $i^{r}$. As such, the problem has been converted to a conventional network equilibrium problem.

Then, the following iterative algorithm is proposed to estimate $\mathbf{s}^{Q}$ :

Step o. Initialization. Regardless of resource failure, iteratively add $i$ to $Q$ if $S_{i} \cap Q \neq \varnothing$, until no new nodes can be added; then, set $x_{i}[0]=0$ for all $i \in Q$ and 1, otherwise; next, conduct traffic assignment based on $x_{i}[0]$ to obtain $g_{k}[0]$ for all $k \in I_{t}$;

Step 1. Traffic assignment. Conduct traffic assignment based on $x_{i}[n]$ to obtain demand flow $g_{k}^{\prime}$, and update $g_{k}[n+1]=\left(1-\rho_{n}\right) g_{k}[n]+\rho_{n} g_{k}^{\prime}$;

Step 2. Update resource failure. Construct $Q^{\prime}$ to contain all nodes $i$, where there exists $r \in R$, such that $d_{i}^{r 0}-g_{k_{i}^{r}}[n+1]<\epsilon_{i}^{r}$;

Step 3. Renew failure propagation. Iteratively set $x_{i}[n+1]=0$ for $i \in Q^{\prime}$ or $S_{i} \cap Q^{\prime} \neq \varnothing$, and expand $Q^{\prime}=Q^{\prime} \bigcup\{i\}$, until no nodes can be added;

Step 4. Stopping rule. If $n=N$ or $\sum_{k \in I_{t}}\left|g_{k}[n+1]-g_{k}[n]\right|<\xi$, terminate, otherwise, set $n=n+1$ and repeat Steps 1 to 3 .

Here, $\rho_{n}$ is a decreasing search step such that $\lim _{n \rightarrow \infty} \rho_{n}=0$ and $\sum_{n=0}^{\infty} \rho_{n} \rightarrow+\infty$, $N$ is the maximum iteration number, and $\xi$ is the small positive threshold. 


\subsection{Alternative model formulations}

In addition to the original model formulation, there are two additional ways in which the model has been modified in order to address specific end-user questions:

1. How can the model be modified to reflect certain aspects of uncertainty, such as uncertainty in exactly how fragile a given node is under disruption?

2. After some infrastructure nodes have been damaged, how can this network be used to decide which nodes need to be restored to maximize social impact?

These questions are addressed via specific modeling techniques as explained in the subsections that follow.

\subsubsection{Probabilistic failure using Monte-Carlo simulations}

An end-user might want to know how to represent a case where there is incomplete information about the true fragility of infrastructure under the given failure propagation mechanisms. In this modification, rather than presuming that infrastructure failure occurs completely and consistently when certain predefined failure conditions are met, instead probabilistic failure analysis is used, whereby each failure propagation occurs based on a certain predefined probability of failure. This technique can help model results under incomplete information because the mean, range, and distribution of the results of multiple model runs can be analyzed to understand the implications of uncertainties in input failure probabilities.

In the Monte-Carlo case study, a failure probability for all facilities of 0.9 was used, and 300 model iterations were run. In a single iteration, all facilities have status values that are either o or 1 for representing nonfunctioning or functioning. However, when these iterations were combined and the mean status was used to represent overall model behavior, it was noted that what counts as failure needed to be defined, given that mean status results would no longer be represented as integer values of 0 and 1. The number of failed facilities in each sector were counted under the Monte-Carlo simulation as if a final mean status constitutes failure if it is less than 0.5 . 


\subsubsection{Restore, recover, and rebuild using the genetic algorithm}

In the "Restore-Recover-Rebuild" case study, the team was given an already-disrupted system and a set of nodes that could be restored or even rebuilt in new locations. The infrastructure network model was viewed as a function that maps each subset of possible combinations of nodes to be restored to a set of social welfare indicators, such as the cumulative time for all communities to access water, markets, healthcare, etc. A method can then be set up to explore the best possible combination of nodes to restore, given that aim is to maximize social benefits while only restoring/rebuilding a certain fixed number of nodes at any point in time. This method translates mathematically to a nonlinear non-convex optimization problem, which can be solved approximately but efficiently by using a genetic algorithm. In this method, rather than performing an exhaustive and computationally expensive calculation that runs all possible restoration scenarios and compares all resulting social welfare indicators to find the optimum solution, the following steps were taken:

- select a smaller population of candidate solutions (node combinations to restore),

- run the model on them and select the best-performing solutions,

- modify the solutions by crossover (random mixing of parts of two good solutions) and mutation (random perturbation of a solution),

- run the model on those solutions again, and

- use the resulting social welfare indicators to discard underperforming modifications, returning the more successful modifications to the population pool.

The process is then repeated a certain number of times to explore the problem space. The process can be modified to optimize solutions for a particular social indicator, a particular neighborhood, or an area of the city most of interest to an end user.

In the results below, the case is shown where, after the disruption of all medical facilities, the effects of restoration of an existing medical facility were compared with the construction of new facilities. The pool of potential locations for new construction was constrained to the locations of existing community nodes. 


\subsection{Beta model}

A number of other modifications were now made to the original (Alpha) model to account for common behaviors of physical and economic systems not previously represented. The second (Beta) model version that addresses these behaviors is described below:

- Rather than a binary facility status of fully failed or fully functional, the facility status was represented along a continuum from o to 1 , so that minor malfunctions and associated reduced capacity can be represented. Let $x_{i} \in[0,1]$ be the working status of each node $i$, where the node is fully functioning if $x_{i}=1$, completely failed if $x_{i}=0$, and partially working otherwise.

- A "resource limit" or "service capacity" was defined, such that no facility can be presumed to offer infinite resources during a given model iteration. Define $\bar{\lambda}_{j}>0$ and $\underline{\lambda}_{j} \geq 0$ to be, respectively, the maximum and minimum service capacity of facility $j$.

- This service capacity is further associated with facility status, such that the resource limit of the facility scales linearly between the minimum and maximum capacity values, according to its status:

$$
\lambda_{j}=x_{j} \bar{\lambda}_{j}+\left(1-x_{j}\right) \underline{\lambda}_{j}, \forall j \in I_{r}, \forall r \in R
$$

- In the Alpha model, although queuing cost was mathematically represented as an M/M/1 queue, the fact that service capacity was unlimited meant that this queuing cost was in practice always zero, and the total calculated cost was a function of transportation costs only. Under the new consideration of limited resources, this "queuing" (which can represent the rate of resource production to resource consumption as well as the idea of "waiting in line to be served") can now correctly result in access costs associated with transportation costs and queuing costs.

- Furthermore, the elasticity of demand was represented in the Beta model. The Alpha model presumed that demand for a resource was constant below a certain cost threshold, at which point the consumer could no longer afford the resource, and demand collapsed completely. In the Beta model, demand decreases as a function of increasing cost to 
represent the fact that people often make do with less as costs rise, rather than waiting to hit some cost ceiling and then being forced to make do with nothing.

- In order to compute system equilibrium on a network that includes these new components of queuing cost and demand loss, an expanded network (Figure 6) was introduced with additional nodes that:

○ funnel all resource acquisitions through "queuing nodes" that track queuing costs,

- provide a "sink" node linked to each facility seeking a resource, to which the value of community demand is passed, and

- create a "dummy" node for each community that bypasses the roads, the resource locations, and the queuing nodes to track the fraction of a community that no longer uses the service when demand falls.

Computing the Nash equilibrium on this augmented network means that a flow pattern is found in it, such that each resource user finds its best strategy, i.e., choosing resource retrieval path and resource supply location (or giving up the need for resource), and facility working status (and hence service capacity) agrees with their weak support input based on its incoming resource flow.

Figure 6. Augmented network representation.

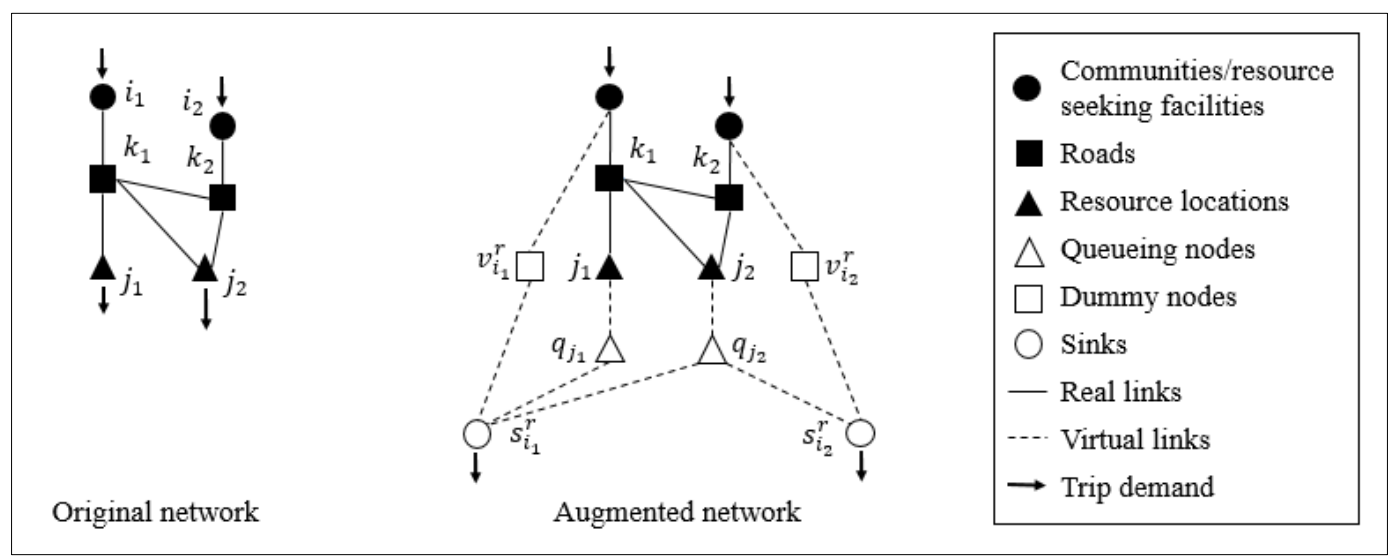




\section{Results}

In this section, different versions of the conceptual model are implemented to analyze the social impact of infrastructure failure based on the conceptual model's combination of real-world and inferred data from the city of Maiduguri, Nigeria.

\subsection{Alpha model results}

\subsubsection{Case Study AO}

The residential communities in the urban area of Maiduguri are categorized into four groups based on their incomes; these categories are middleincome, mixed middle-income and commercial, poor-income, and shantytown. Their geographical distributions are shown in Figure 7, overlaid on population density. The population distribution is observed to be clustered near the city center (where the population has mostly higher income), and it gradually diminishes to the peripheral (where the population has mostly lower income). The population of each community polygon was estimated by using the LandScan2010 dataset (ORNL 2010). The resource demand for community $i \in I_{c}$ was further estimated by:

$$
d_{i}^{r 0}= \begin{cases}d_{i}^{P}, & \text { if } r \in\{\text { water, food }\} \\ 0.4 d_{i}^{P}, & \text { if } r \in\{\text { education, healthcare }\} \\ 0, & \text { otherwise }\end{cases}
$$

where $d_{i}^{P}$ is the population of community $i$. The factor 0.4 reflects the resource demand for education, and healthcare is relatively less critical than water and food. In addition, an inverse demand function of resource $r$ for community $i$ was considered as:

$$
D_{i}^{r}\left(c_{i}^{r} ; d_{i}^{r 0}\right)= \begin{cases}d_{i}^{r 0}, & \text { if } c_{i}^{r}<\max \left\{0.6 \hat{c}_{i}^{r}, 10 c_{i}^{r 0}\right\}, \\ 0, & \text { otherwise }\end{cases}
$$

where $c_{i}^{r 0}$ is the resource procurement cost under the normal scenario, and $\hat{c}_{i}^{r}$ is the maximal resource procurement cost among the community in the same category as $i$. This is to say, a community with higher $c_{i}^{r 0}$ is more robust under disruption since its people are relatively accustomed to 
the high-cost (time) life style. On the contrary, a community with low $c_{i}^{r 0}$ becomes relatively sensitive to the cost increase under disruption. Here, to avoid unrealism, $\hat{c}_{i}^{r}$ is introduced to represent the minimum affordability to communities with extremely low $c_{i}^{r 0}$.

Figure 7. Maiduguri community and population distribution.

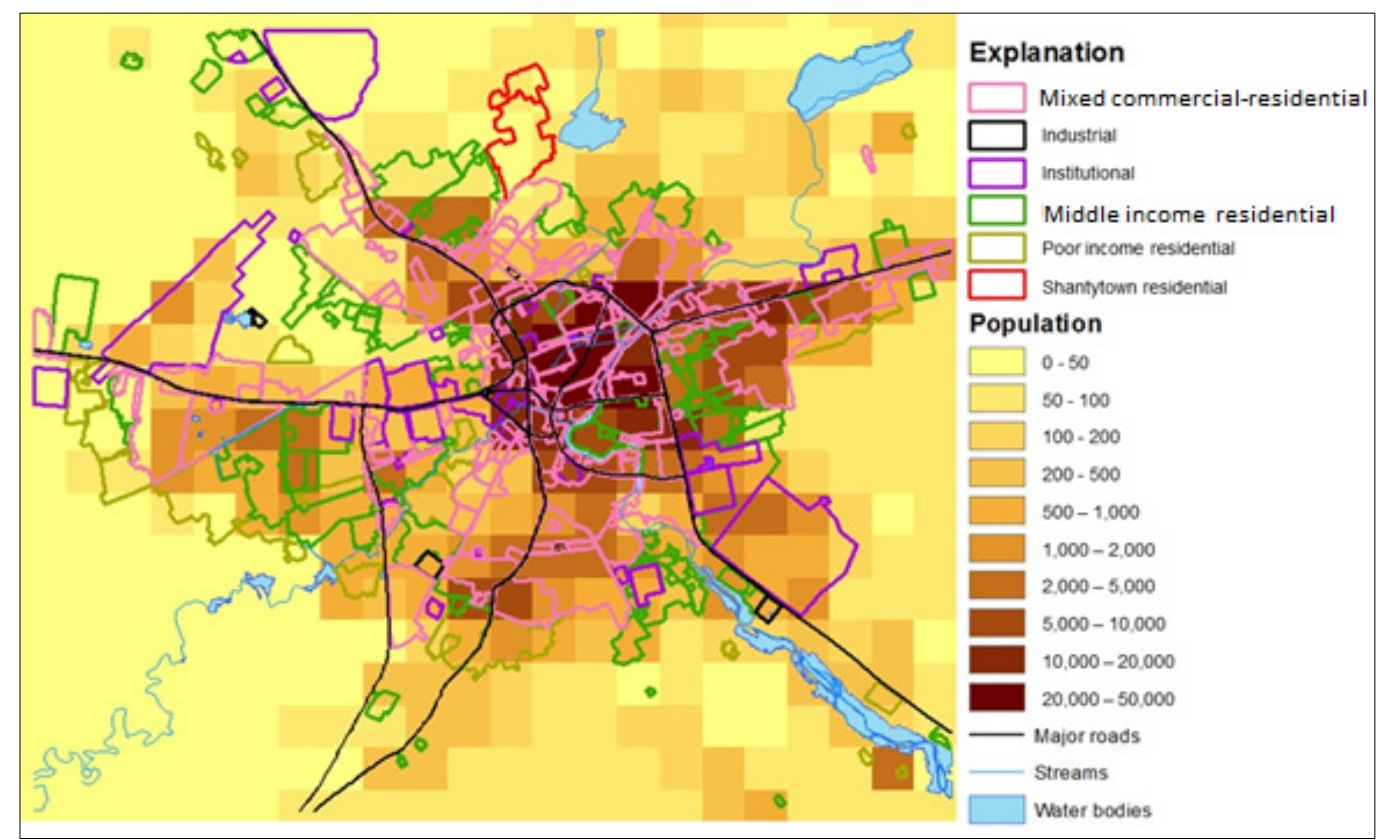

The infrastructure locations are presented in Figure 8, where each point indicates an infrastructure node, and the type/layer is differentiated by the marker shape. The structure of the seven infrastructure layers are described in detail in a previous section, but are summarized here as follows: (i) the electricity layer supports the water layer, and they jointly support education and healthcare layers; (ii) the transportation layer neither is supported nor supports other layers, but purely provides mobility to the system; (iii) the food layer only provides food to the community, where the downstream food market node seeks supply from the upstream food processing facilities; and (iv) the fuel layer only provides fuel to the infrastructure nodes such as those in the electricity layer. The resource demand of the infrastructure node normally does not generate huge traffic, hence $d_{i}^{r 0}=1$ was assigned for each infrastructure node that would be seeking resources (e.g., fuel and food); the inverse demand function of an infrastructure $i$ is 


$$
D_{i}^{r}\left(c_{i}^{r} ; d_{i}^{r 0}\right)= \begin{cases}d_{i}^{r 0}, & \text { if } c_{i}^{r}<\max \left\{0.6 \hat{c}_{i}^{r}, 1.2 c_{i}^{r 0}\right\} \\ 0, & \text { otherwise }\end{cases}
$$

where the factor 1.2 is smaller than that of a community. This is because the flexibility to change a resource supplier for the infrastructure is normally far less than that of a resource supplier. It should also be noted that some infrastructure node within a resource layer might not directly provide resources but support other downstream resource node, which includes water treatment plants, fuel central depot, and food processing facilities.

Figure 8. Maiduguri infrastructure distribution.

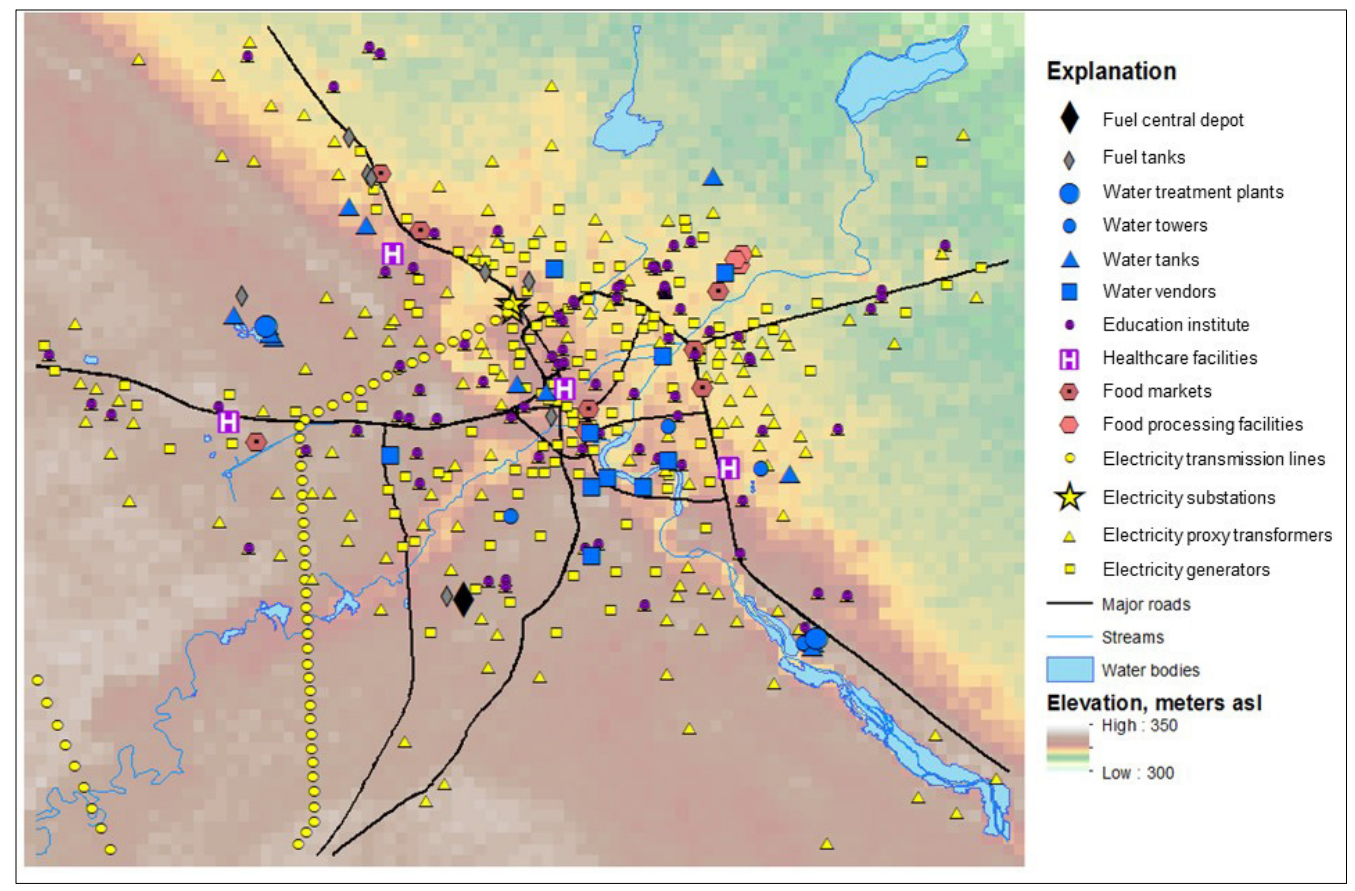

The rest of the parameters are set as follows: $\alpha_{k}=0.15 \mathrm{~min}, \beta_{k}=4$, $\gamma_{k}=10,000$ vehicles per lane per day, $\delta_{k}$ is computed based on actual distance between nodes at a free-flow speed of $35 \mathrm{mph}, \lambda_{k}$ is set to be infinity to indicate the resource supply is sufficient, $\epsilon_{i}^{r}=d_{i}^{r 0}$ for $i \in I \backslash I_{c}$, and for running the algorithm, $N=50$ and $\rho_{n}=1 / n$.

A scenario was considered wherein disruption initiates at the only power substation and then the failure propagation and social impacts were investigated. The electricity substation is a critical node that supports a variety 
of other infrastructure nodes, including water treatment plants and electricity transformers. After implementing this algorithm, the system converges to an equilibrium, and the infrastructure status is shown as Figure 9. As expected, all electricity transformers are shut down, the electricity network is disabled, while only local electricity generators can work based on fuel, providing very limited (and expensive) power supply to nearby communities. Furthermore, the water network is also disrupted, while only local water vendors can pump water from wells. As a result, educational institutions and healthcare facilities are all disrupted due to the shortage of power and water. In addition, a fuel tank fails because the cost to get fuel supply from the central fuel depot becomes too high due to local congestion.

Figure 9. Status of infrastructure components after a cascading disruption.

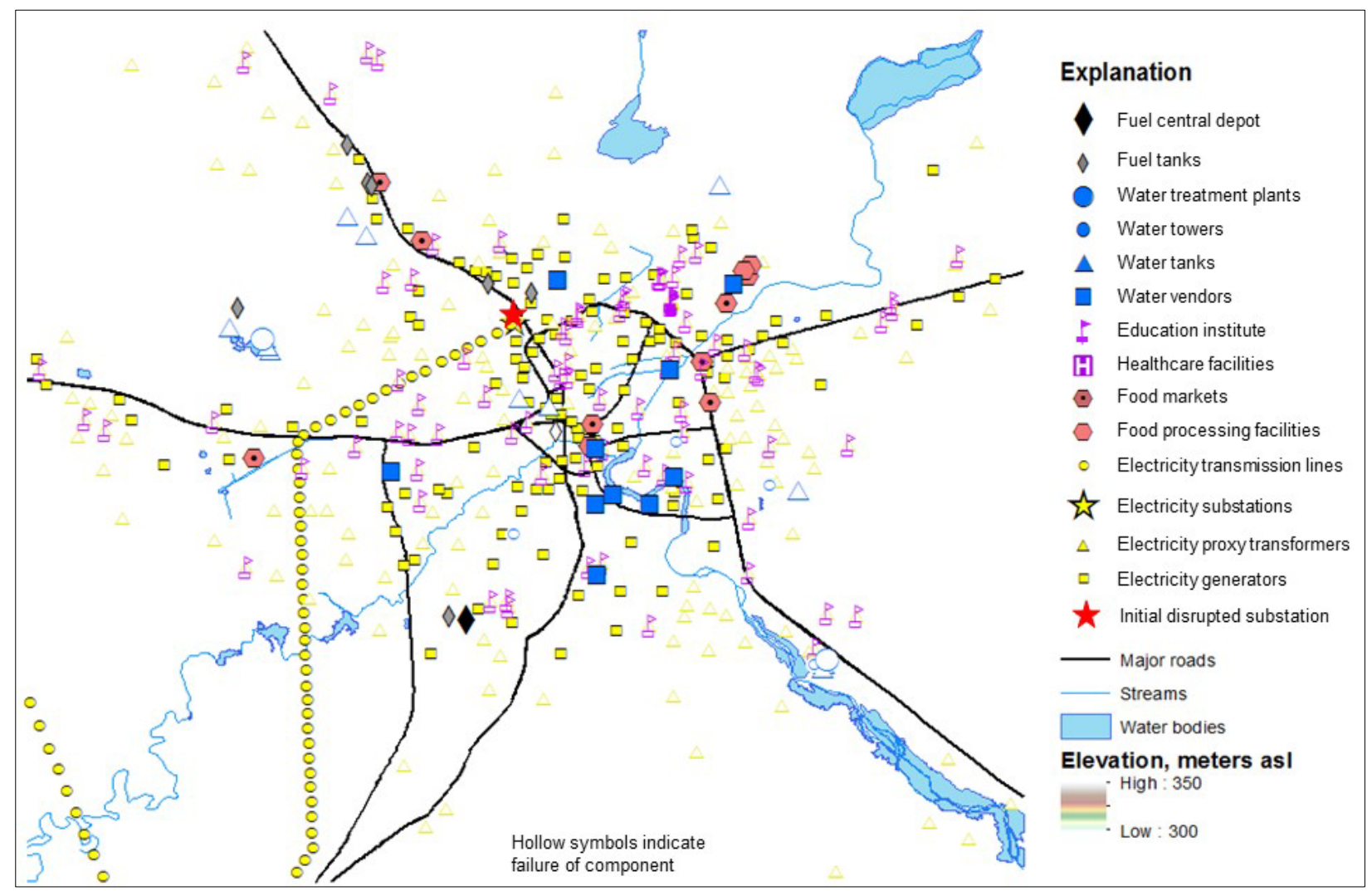

The social impacts are estimated as follows. In total, $64 \%$ of the water nodes, $0 \%$ of the food nodes, $11 \%$ of the fuel nodes, and $100 \%$ of education and healthcare nodes are disrupted (i.e., $\Delta_{x}^{\text {water }}=18, \Delta_{x}^{\text {food }}=0, \Delta_{x}^{\text {fuel }}=1$, $\Delta_{x}^{\text {education }}=84$, and $\left.\Delta_{x}^{\text {healthcare }}=4\right)$. Interestingly, after disruption, the average access cost for food even decreases from 0.75 to 0.54 . This is mainly due to the loss of education and healthcare needs which relieve traffic congestion 
in some parts of the city. The overall average access cost for water is almost unchanged for the same reason. A detailed look of the spatial distribution of community's water access cost is shown in Figure 10. Compared to that in the normal scenario, the cost in the southwest region, which was previously very high due to existing congestion, significantly decreases due to the reduced travel demand. In contrary, in other regions, the cost slightly increases as original water suppliers were likely to be disrupted.

Figure 10. Community water costs before (top) and after (bottom) disruption.
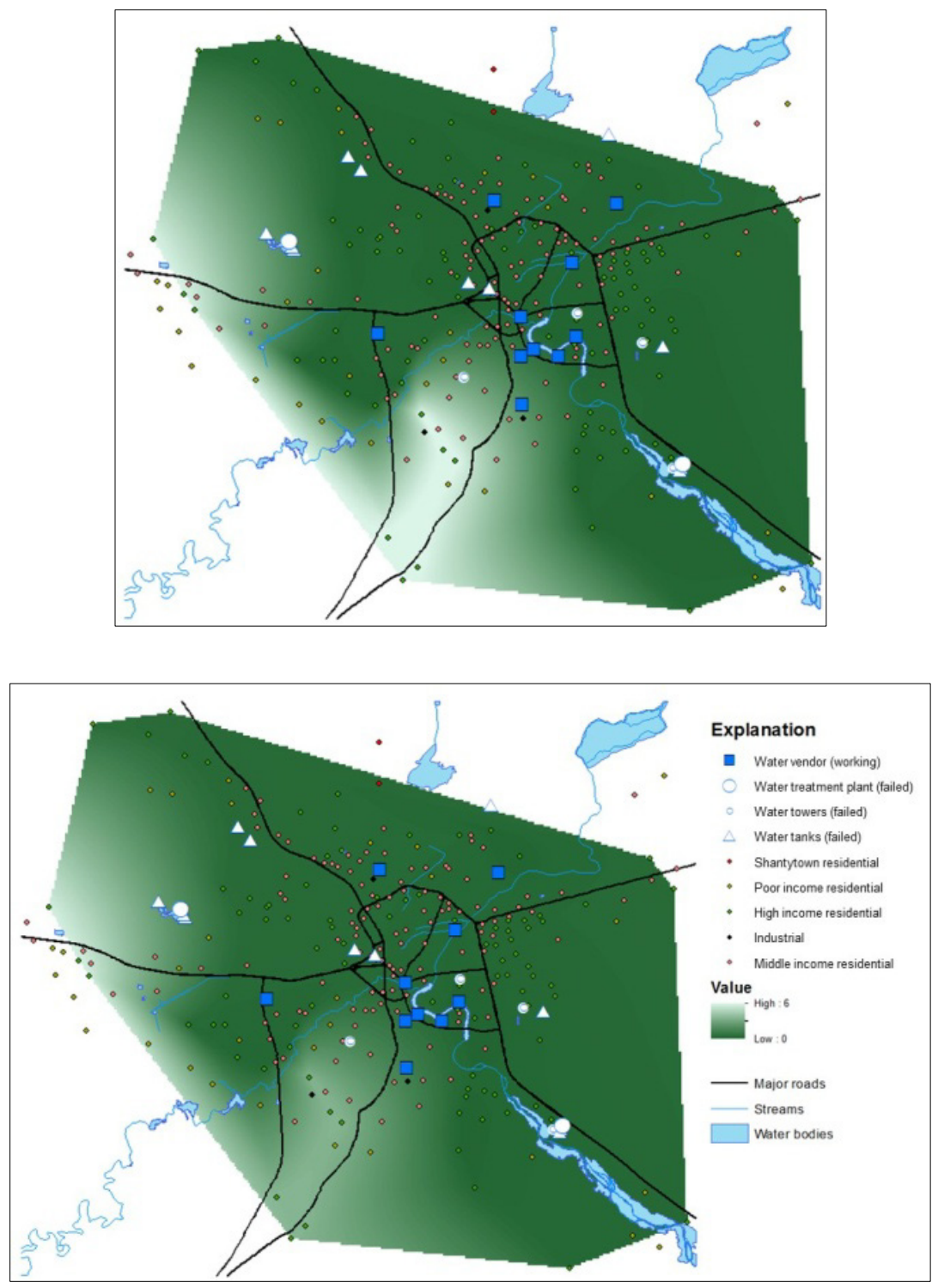


\subsubsection{Case Study A1}

For a second case study scenario in Maiduguri, a situation was introduced in which failure is caused to one of four water towers supplied by clean water via the water treatment plants. Both before and after the failure, the user equilibrium algorithm calculates an access cost distribution over all the communities that require the resource such that after the equilibrium is calculated, no individual user can unilaterally lower his or her access costs by choosing to obtain the resource from a different location. These access cost results are provided at the point locations of the communities at which they are calculated. These points can then be interpolated to create a cost map (Figure 11). This image shows that costs are lowest for communities nearer to the water towers, while a band of higher-cost access is observed to run north-south through the western part of the city. The cost value calculated is a relative number, not intended to represent monetary units.

When the northernmost water tower fails, the user equilibrium is recalculated, and the ratio of the access costs before and after the failure can be displayed (Figure 12). This mapping clearly delineates the areas that would be most immediately affected by the loss of this particular infrastructure component. The locations of residential communities of varying income levels are overlaid on this cost ratio map. Note that many residential communities within the area most affected by the loss of infrastructure are middle-income areas and only two are poor or shantytown areas. The majority of the highly affected areas are mixed-use commercial/residential areas (not shown in Figure 12 for readability reasons; mixed-use communities are mapped in Figure 7). 
Figure 11. Initial water access costs in case study A1.

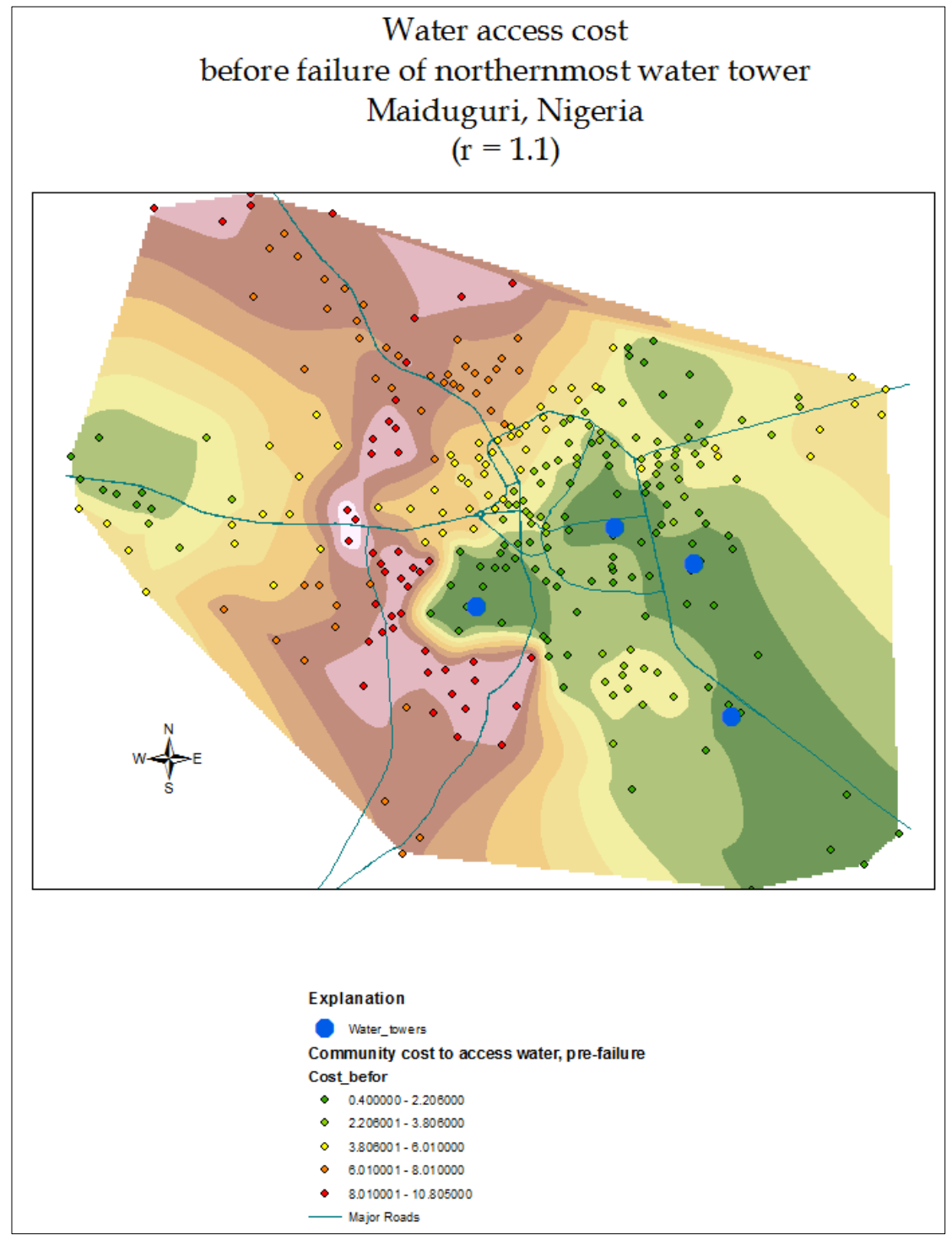


Figure 12. Water access cost ratio, final, case study A1 .

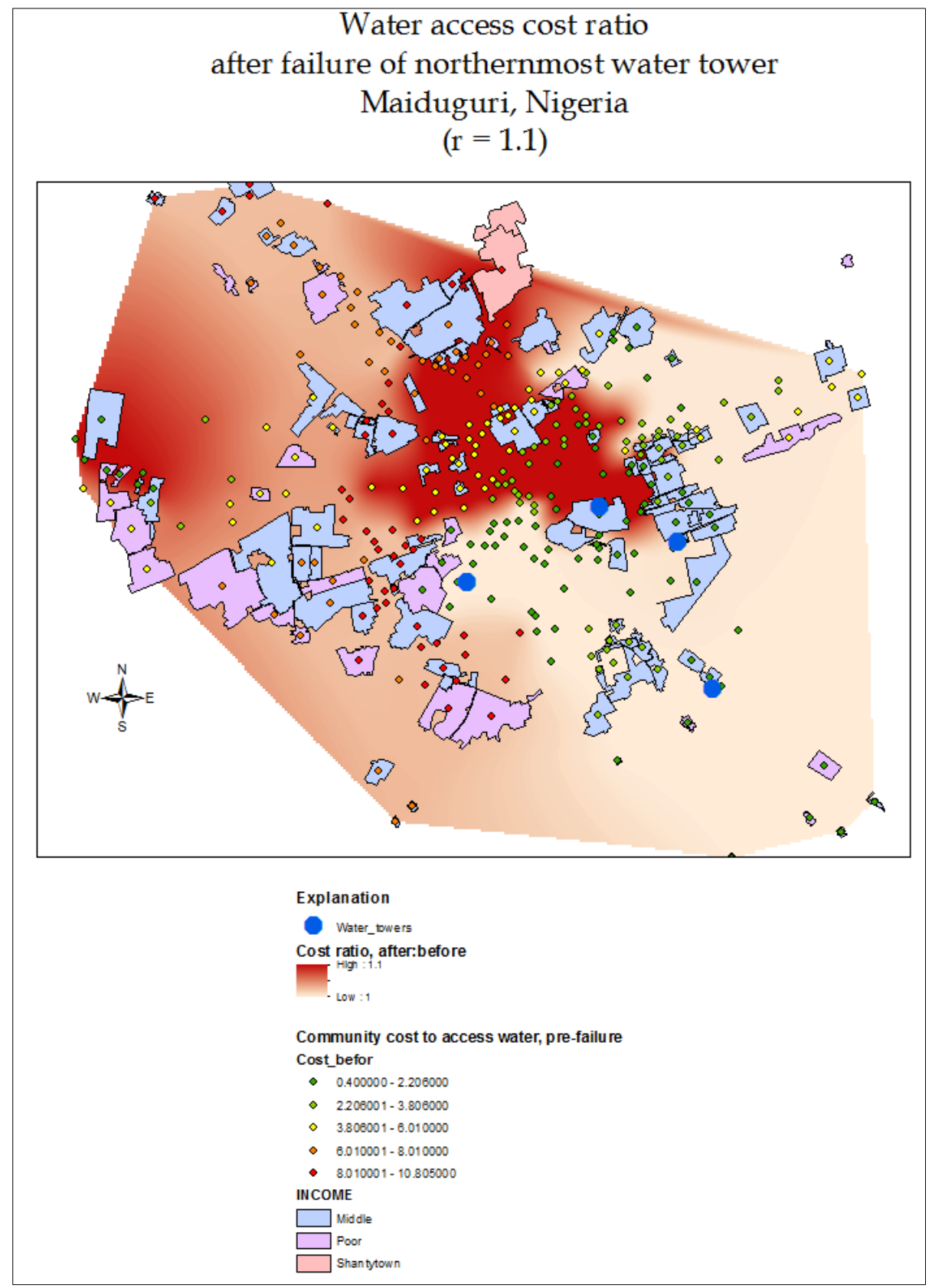

\subsubsection{Alpha model sensitivity analysis}

The above Case Study Ao (outlined in 3.1.1) is denoted as a benchmark Scenario o, and it now examines several representative scenarios under different parameter settings. The corresponding societal impacts are summarized in Table 1. 
First, in Scenarios 1 and 2, the flexibility for an infrastructure to change resource supplier is perturbed. For example, the coefficient of $c_{i}^{r 0}$ in Equation 18 . Scenario 1 suggests that, with a lower flexibility to change, infrastructures are more vulnerable to disruption caused by resource flow congestion/queuing. Compared with the benchmark scenario, more infrastructure (including five water vendors and three food markets) are disrupted due to resource failure. Consequently, the average food access cost increases by $95 \%$, and now $0.9 \%$ of the population has lost its food supply. Further, the average water access cost dramatically increases-by more than five times that in the normal scenario-since only five water nodes now remain working. These results imply that the system can be very sensitive to the infrastructure's flexibility for changing suppliers. This result is due mainly because of the system's positive feedback to the traffic congestion (i.e., stubborn-to-change infrastructures are likely to have resource failure and intensify the traffic congestion, which in turn further prevent the change of suppliers). On the other hand, the system is more robust at a higher infrastructure flexibility, as shown in Scenario 2. The only noticeable change is the survival of the fuel tank that was disrupted in the benchmark scenario.

Next, in Scenarios 3 and 4, the impact of having a smaller road capacity is considered. The results are quite dramatic. Compared with the benchmark scenario, $10 \%$ of capacity reduction can cause severe food and water cost increases and demand losses. This comparison confirms how resource failures can sweep down the infrastructure system. However, it should also be noted that the social impacts at $10 \%$ and $25 \%$ capacity reduction are relatively close (e.g., there exists a diminishing marginal impact). This diminishing impact may occur because most communities have lost service even at $10 \%$ capacity reduction.

Table 1. Sensitivity analysis results.

\begin{tabular}{|c|c|c|c|c|c|c|}
\hline \multirow[b]{2}{*}{ Scenarios } & \multicolumn{3}{|c|}{ Food } & \multicolumn{3}{|c|}{ Water } \\
\hline & $\begin{array}{l}\text { Access } \\
\text { Cost } \\
\text { Increase }\end{array}$ & $\begin{array}{l}\text { Demand } \\
\text { Loss }\end{array}$ & $\begin{array}{l}\text { \#Node } \\
\text { Failed } \\
\text { (Total 11) }\end{array}$ & $\begin{array}{l}\text { Access } \\
\text { Cost } \\
\text { Increase }\end{array}$ & $\begin{array}{l}\text { Demand } \\
\text { Loss }\end{array}$ & $\begin{array}{l}\text { \#Node } \\
\text { Failed (Total } \\
\text { 28) }\end{array}$ \\
\hline 0: Case Study & $-36 \%$ & $0.0 \%$ & 0 & $0.5 \%$ & $0.0 \%$ & 18 \\
\hline${ }_{1:} 1.1 c_{i}^{r 0}$ & $95 \%$ & $0.9 \%$ & 3 & $531 \%$ & $55.2 \%$ & 23 \\
\hline 2: $1.3 c_{i}^{r 0}$ & $-37 \%$ & $0.0 \%$ & 0 & $0.5 \%$ & $0.0 \%$ & 18 \\
\hline
\end{tabular}




\begin{tabular}{|c|c|c|c|c|c|c|}
\hline \multirow[b]{2}{*}{ Scenarios } & \multicolumn{3}{|c|}{ Food } & \multicolumn{3}{|c|}{ Water } \\
\hline & $\begin{array}{l}\text { Access } \\
\text { Cost } \\
\text { Increase }\end{array}$ & $\begin{array}{l}\text { Demand } \\
\text { Loss }\end{array}$ & $\begin{array}{l}\text { \#Node } \\
\text { Failed } \\
\text { (Total 11) }\end{array}$ & $\begin{array}{l}\text { Access } \\
\text { Cost } \\
\text { Increase }\end{array}$ & $\begin{array}{l}\text { Demand } \\
\text { Loss }\end{array}$ & $\begin{array}{l}\text { \#Node } \\
\text { Failed (Tota } \\
\text { 28) }\end{array}$ \\
\hline 3: $90 \% \delta_{k}$ & $536 \%$ & $78.1 \%$ & 7 & $465 \%$ & $56.2 \%$ & 23 \\
\hline 4: $75 \% \delta_{k}$ & $601 \%$ & $80.0 \%$ & 7 & $531 \%$ & $58.3 \%$ & 23 \\
\hline 5: Initial Water & $3 \%$ & $0.0 \%$ & 0 & $6 \%$ & $0.0 \%$ & 7 \\
\hline 6: Initial Fuel & $25 \%$ & $0.0 \%$ & 0 & $100 \%$ & $0.0 \%$ & 14 \\
\hline $\begin{array}{l}\text { 7: Initial Fuel \& Water; } \\
1.3 c_{i}^{r 0}\end{array}$ & $72 \%$ & $1.9 \%$ & 1 & $149 \%$ & $7.6 \%$ & 17 \\
\hline
\end{tabular}

Scenario 5 explores a different initial disruption at a water treatment plant. Counter-intuitively, although water treatment plant is the key infrastructure in the water layer, shutting it down does not significantly affect the entire system. Although three water towers (due to support failure) and four water tanks (due to resource failure) are disrupted, the water access cost only slightly increases by $6.0 \%$, and there is no water demand loss. This is mainly because ten local water vendors can still independently provide water to the population despite the water network disruption. Further, no disruptions are found in the food layer, although the increase in traffic congestion (due to water shipments) still causes a $3 \%$ increase in the average food access cost.

In Scenario 6, it is assumed that the initial disruption occurs at the central fuel depot, which directly cuts down the fuel supply to the entire system. As a result, ten local water vendors are all disrupted (due to resource failure) and four water tanks are further disrupted due to congestion/queuing (due to increased water shipment flow). However, the community can still survive well without fuel supply, whereas only access costs for food and water bear some modest increases. Therefore, the fuel layer does not play a critical role in the infrastructure system if the power grid and water network still function well.

Finally, in Scenario 7, the central fuel depot is still considered as the initial disruption node, but the infrastructures' flexibility to change suppliers is increased to 1.3. The result appears to be quite counter-intuitive at first glance. Even more infrastructures are disrupted in this scenario than in Scenario 6. This "paradoxical" observation is a reflection on the interesting 
interdependency due to self-interested competitions among different infrastructures. When a certain amount of infrastructures shut down, as in Scenario 6, other unrelated infrastructure will survive better as congestion/queuing becomes mitigated and resource procurement becomes easier. On the contrary, the survival of a smaller number of infrastructures may boost traffic congestion and even disrupt unrelated infrastructures that are more sensitive to resource failure.

\subsection{Alternative model results}

\subsubsection{Probabilistic failure with Monte-Carlo simulation}

The results of using a probabilistic failure scheme with a uniform failure probability of 0.9 shows that after 300 iterations, the mean number of functioning nodes does indeed change significantly across most sectors from the deterministic benchmark case (Table 2). However, it is clear that being able to establish even the direction of that change depends on how failure is ultimately defined. Therefore, it is recommend that more care be taken to establish how resource failure is defined within the model, which is addressed further in Section 3.3.

Table 2. Number of facility failures, by sector, under probabilistic failure scenario.

\begin{tabular}{|c|c|c|c|c|}
\hline \multicolumn{5}{|c|}{$\begin{array}{c}\text { Failure of Facilities } \\
\text { (Failure Probability }=0.9,300 \text { iterations) }\end{array}$} \\
\hline Level & Total number & $\begin{array}{l}\text { Benchmark case } \\
\text { (deterministic) }\end{array}$ & $\begin{array}{l}\text { Monte-Carlo simulation } \\
\text { (count as failure if } \\
\text { survival rate }<0.5 \text { ) }\end{array}$ & $\begin{array}{l}\text { Monte-Carlo simulation } \\
\text { (count as failure if } \\
\text { survival rate }<0.1 \text { ) }\end{array}$ \\
\hline Total & 544 & 320 & 428 & 167 \\
\hline Power & 408 & 213 & 309 & 117 \\
\hline Fuel & 9 & 1 & 7 & 0 \\
\hline Food & 11 & 0 & 1 & 0 \\
\hline Water & 28 & 18 & 23 & 2 \\
\hline Education & 84 & 84 & 84 & 45 \\
\hline Medical care & 4 & 4 & 4 & 3 \\
\hline
\end{tabular}




\subsubsection{Restore, recover, and rebuild using the genetic algorithm}

Figure 13 (a-d) show the costs associated with access to medical facilities under different situations: (a) initial state, before disruption; (b) after disruption, where costs increase significantly; (c) costs after one of the medical facilities is restored; and (d) costs after the genetic algorithm has evaluated the optimum placement for two new hospitals (without rebuilding the old ones), in which lower overall costs are seen across the city. Note that in these figures, the scales are not equivalent in order to show the geospatial differentiation produced by the network model equilibrium.

Figure 13. Medical facilities access costs under Repair-Restore-Rebuild scenario, (a) prior to disruption (low costs), (b) after disruption (high costs), (c) after restoration of one previously existing facility (moderate costs), (d) after rebuilding in two new locations (relatively low costs) as optimized using the genetic algorithm. Note that image colors are scaled differently between the scenarios, but always with light blue representing the lowest cost and bright pink representing the highest cost.

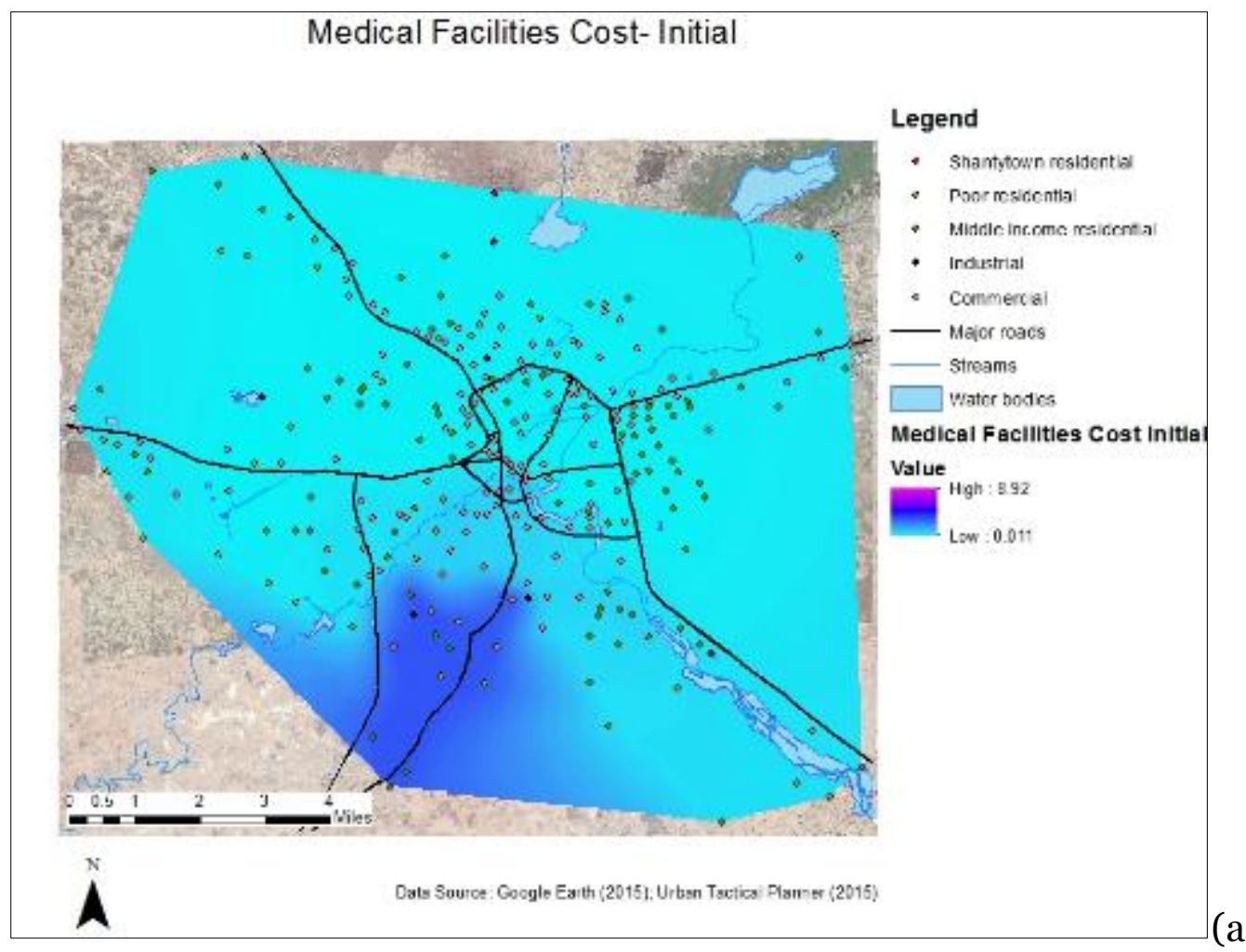




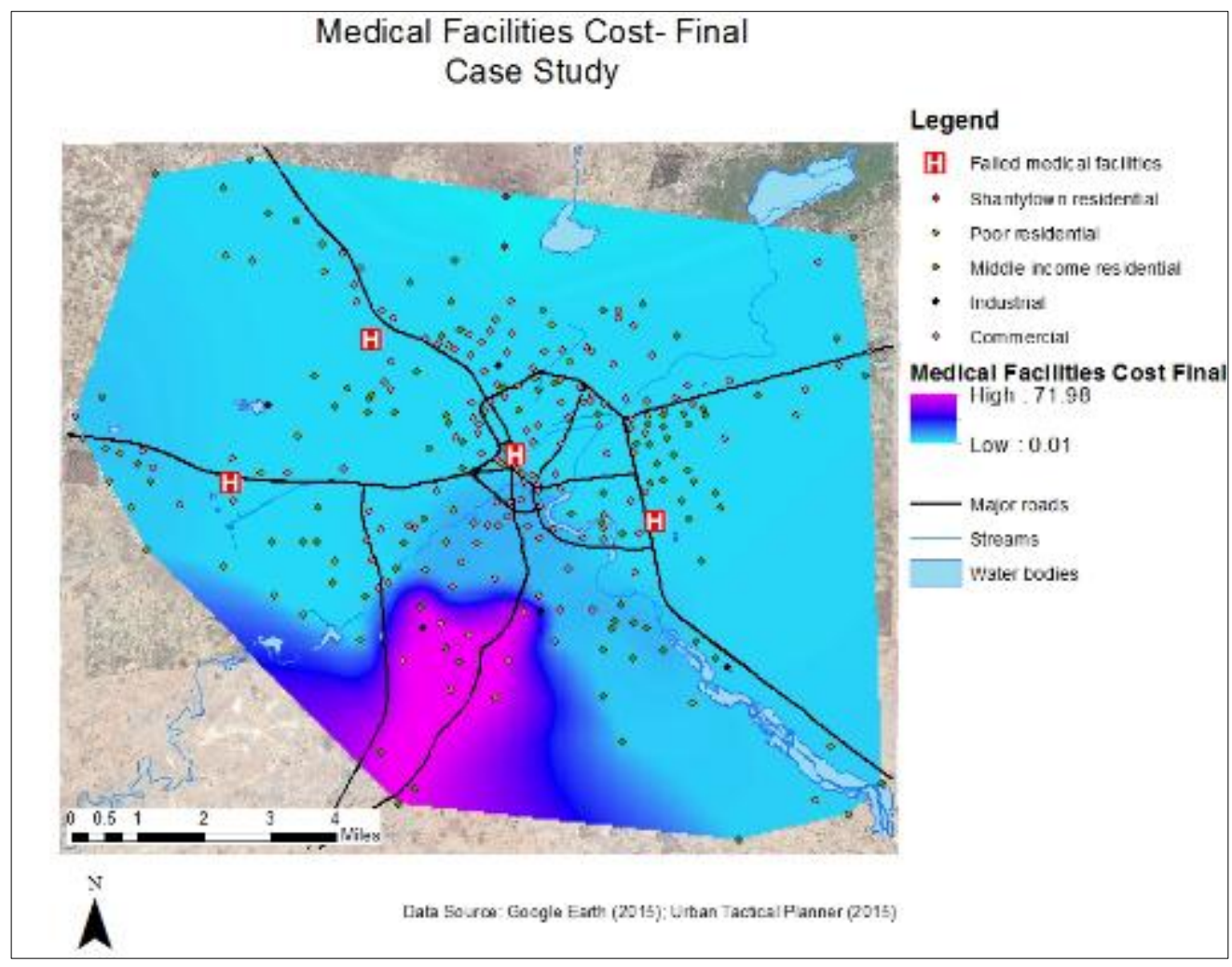

(b)

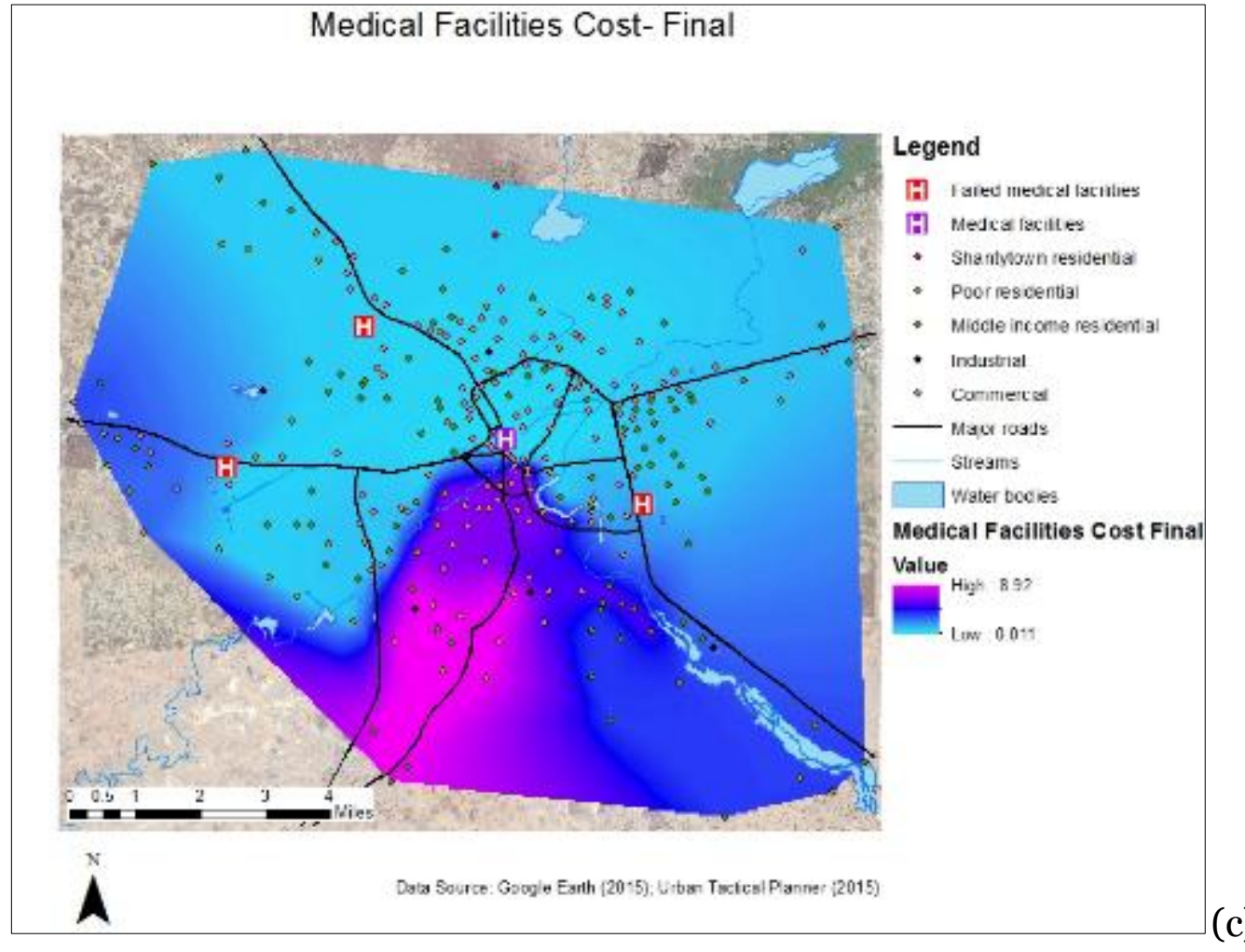




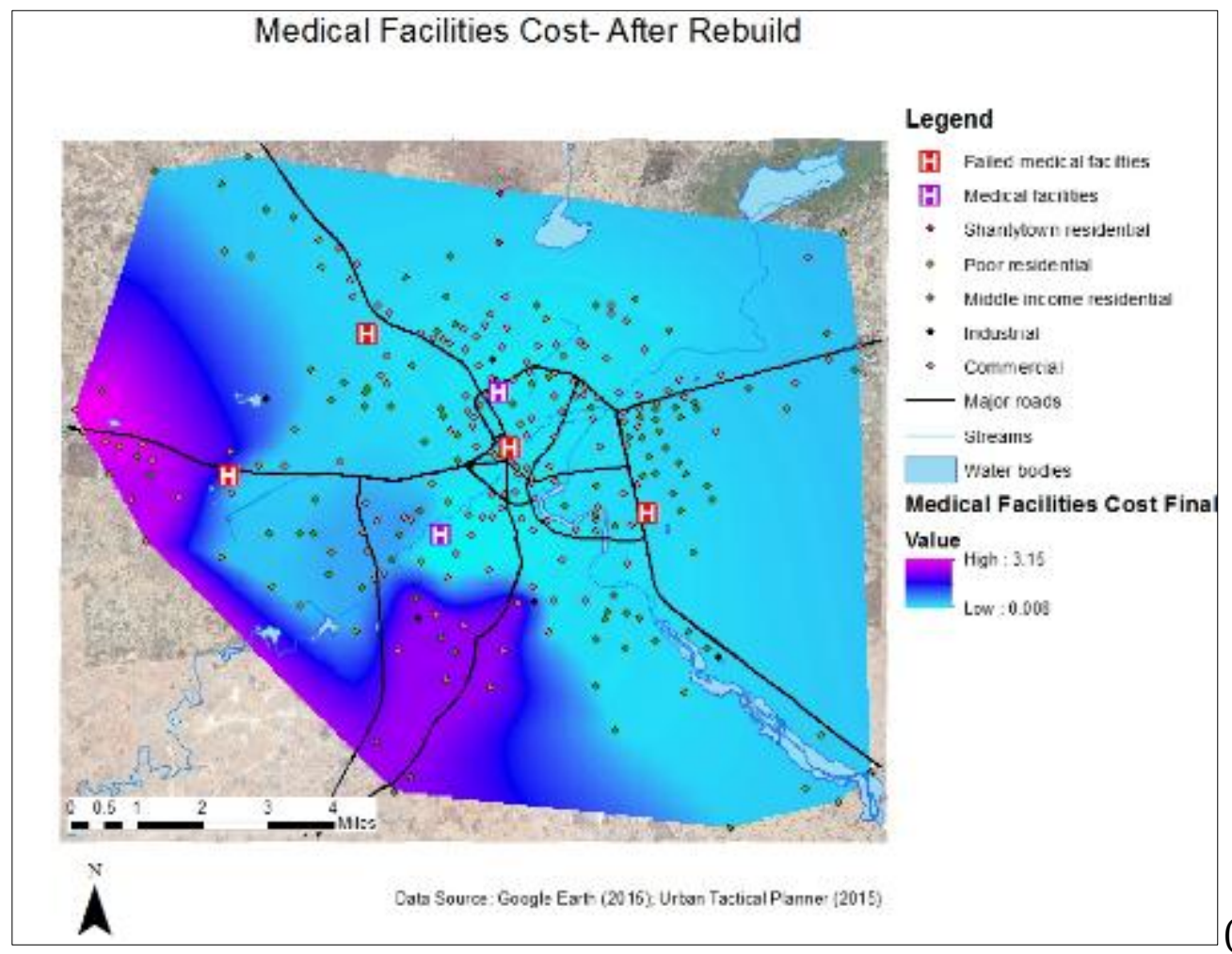

(d)

\subsection{Beta model results}

\subsubsection{Case Study BO}

As in Case Study Ao, a scenario was considered where disruption initiates at the main power substation in the center of the city, and the failure propagation and social impacts are then investigated. After implementing the Alpha model's algorithm, the system converges to an equilibrium, and the resulting infrastructure status is shown in Figure 14, where a component having a working status less than 0.5 is represented by a hollow symbol to indicate either complete or partial loss of functionality. As expected, all electricity transformers are shut down, the electricity network is disabled, while only local electricity generators can work based on fuel, providing limited power supply to nearby communities. Furthermore, the water network is also disrupted, while only local commercial water vendors that can pump water from wells using generators still function. As a result, educational institutions and healthcare facilities are all disrupted due to the shortage of power and water.

The social impacts are estimated as follows. In total, $62.4 \%$ of the water nodes, $0.0 \%$ of the food nodes, $0.0 \%$ of the fuel nodes, and $100.0 \%$ of education and healthcare nodes are disrupted (i.e., $\Delta_{x}^{\text {water }}=17.5, \Delta_{x}^{\text {food }}=0.0$, 
$\Delta_{x}^{\text {fuel }}=0.0, \Delta_{x}^{\text {education }}=84.0$, and $\left.\Delta_{x}^{\text {healthcare }}=4.0\right)$. There is no demand loss for water and food, but all demand for education and healthcare are lost. Interestingly, after disruption, the average access cost for food even decreases from 0.35 to 0.32 . This is mainly due to the loss of education and healthcare needs, which relieves traffic congestion in some parts of the city. The overall average access cost for water increases from 0.25 to 1.42 , and $4.3 \%$ of population lost access to water, which is caused by the cost increase of queuing at remaining water facilities. The spatial distribution of changes in communities' water access costs shows that costs increased significantly around several of the commercial water providers as competition increases for those limited resources.

Figure 14. Water access cost ratios for Beta Model, Scenario 0.

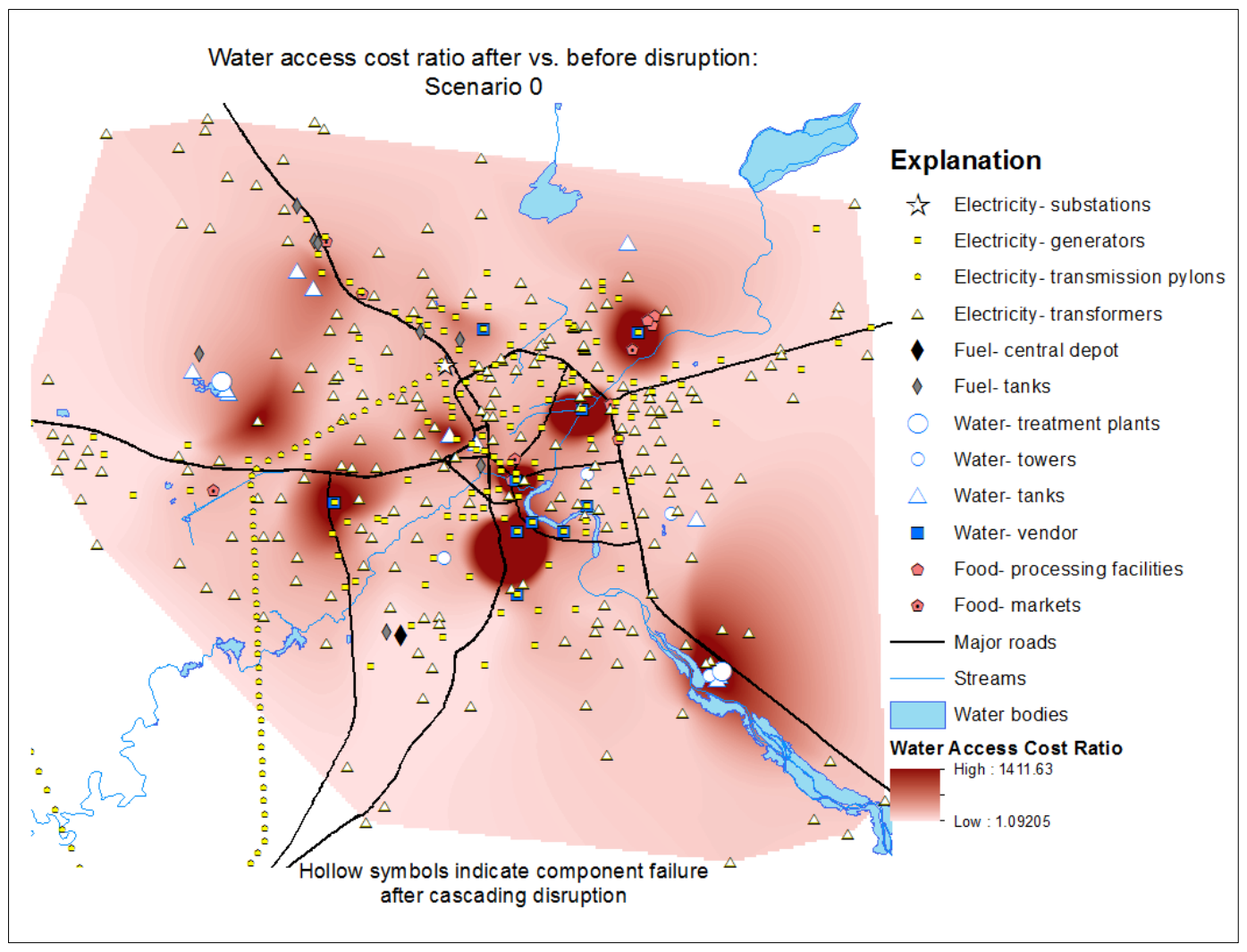

\subsubsection{Beta model sensitivity analysis}

The above case study (Bo) is denoted as benchmark Scenario o, and now six additional, representative scenarios are examined under different parameter settings, focusing on three societal impacts in the food and water sectors and using the Beta Model. Results of all seven scenarios are summarized in Table 3 . 
In Scenario 1, the consideration of queuing cost at resource location was removed. Since the transportation cost is the total access cost, the reduction of traffic leads to a more noticeable decrease in the food access cost. There is no significant change in the water access cost after disruption, which means the negative effect of water facilities failure is cancelled out by the reduced traffic congestion.

Table 3. Societal impacts in the food and water sectors under different scenarios, using the Beta Model.

\begin{tabular}{lllllll}
\hline & \multicolumn{3}{c}{ Food } & \multicolumn{3}{c}{ Water } \\
Scenarios & $\begin{array}{l}\text { Access } \\
\text { cost } \\
\text { increase }\end{array}$ & $\begin{array}{l}\text { Demand } \\
\text { loss }\end{array}$ & $\begin{array}{l}\text { \# Nodes } \\
\text { failed } \\
\text { (total 11) }\end{array}$ & $\begin{array}{l}\text { Access } \\
\text { cost } \\
\text { increase }\end{array}$ & $\begin{array}{l}\text { Demand } \\
\text { loss }\end{array}$ & $\begin{array}{l}\text { \#Node } \\
\text { failed (total } \\
\text { 28) }\end{array}$ \\
\hline 0: Case Study & $-7 \%$ & $0.0 \%$ & 0.0 & $458 \%$ & $4.3 \%$ & 17.5 \\
1: No Queuing & $-36 \%$ & $0.0 \%$ & 0.0 & $0.5 \%$ & $0.0 \%$ & 18.0 \\
2: $\kappa_{\text {cap }}=5.0$ & $-49 \%$ & $0.0 \%$ & 0.0 & $-25 \%$ & $0.0 \%$ & 17.5 \\
3: $\kappa_{\text {cap }}=10.0$ & $-54 \%$ & $0.0 \%$ & 0.0 & $-35 \%$ & $0.0 \%$ & 17.5 \\
4: Initial Water & $-27 \%$ & $0.0 \%$ & 0.0 & $20 \%$ & $2.9 \%$ & 9.3 \\
5: Initial Fuel & $22 \%$ & $1.3 \%$ & 0.5 & $157 \%$ & $5.9 \%$ & 10.6 \\
6: Water and Fuel & $-2 \%$ & $0.0 \%$ & 0.3 & $860 \%$ & $8.7 \%$ & 16.2
\end{tabular}

Scenarios 2 and 3 examine the impact of facility maximum resource capacity $\bar{\lambda}_{j}$. It is expected that an infrastructure system with higher maximum resource capacity would have greater resiliency to system disruption. In Scenario o, let the resource users visit their nearest resource locations and compute the resource capacity of the resource locations based on the demand by multiplying a factor $\kappa_{\text {cap }}$ of 1.1. In Scenario 2 and 3, $\kappa_{\text {cap }}$ is changed to 5.0 and 10.0, respectively, to consider an infrastructure system with moderate and high resource capacity. Similar to Scenario 1, as the queuing cost is reduced, the transportation cost takes a greater portion in the overall access cost; hence, the alleviation of traffic congestion results in a greater percentage reduction in access cost. Decreases of $49 \%$ and $25 \%$ respectively in food and water access cost were observed in Scenario 2, and $54 \%$ and $35 \%$ decreases, respectively, were observed in Scenario 3.

Scenario 4 explores a different initial disruption at a water treatment plant. Counterintuitively, although the water treatment plant is the key in- 
frastructure in the water layer, shutting it down does not significantly affect the entire system. Although 4.0 water towers (due to support failure), 3.0 water tanks, and 2.3 water vendors (due to resource failure) are disrupted, the water access cost only slightly increases (by 20\%), and there is a 2.9\% water demand loss. These numbers are mainly because of the high inelasticity of resource demand of facilities makes resource failure very unlikely to happen. Further, no disruptions in the food layer are found, and there is a decrease of $27 \%$ in food procurement cost due to traffic congestion that causes increased travel.

In Scenario 5, the initial disruption is assumed to occur at the central fuel depot, which directly cuts down the fuel supply to the entire system. As a result, ten local water vendors are completely disrupted (due to resource failure), and the status of several water tanks are impaired due to increased congestion. Similarly, the food markets are also affected due to congestion, with a total status reduction of 0.5. The community can still survive well without fuel supply, whereas the increases in access cost for water and food have a moderate effect. Therefore, the fuel layer does not play a critical role in the infrastructure system if the power grid and water network still function well.

In Scenario 6, the water treatment plant and the fuel depot are both failed in the initial disruption. The result turns out to be more devastating than the simple summation of the results where the two facilities are disrupted. The water access cost is increased by $860 \%$, with $8.7 \%$ of the population having lost water access. The demand loss appears to be low, while there is a dramatic increase in access cost, because of both the inelasticity of resource demand and a relatively insufficient resource supply in the infrastructure system. 


\section{Conclusions}

The goal of this research was to develop a system that can be used by military planners and strategists to incorporate longer-term thinking into conflict analysis, so that both humanitarian assistance and reconstruction strategies can be better visualized during earlier phases of the military planning process.

In this report, a holistic mathematical model has been proposed to evaluate the vulnerability of an urban infrastructure system against the threats of cascading failures. The complex, interdependent infrastructure systems are modeled as a multi-layered network, where each functioning infrastructure unit is modeled as a node in a layer for its type. Two types of infrastructure failure mechanisms are modeled to estimate the cascading failure under a disaster: support failure (e.g., disruption due to loss of direct physical connections) and resource failure (e.g., disruption due to loss of resource supply). To this end, a revised network equilibrium model that incorporates queuing and congestion is formulated, and the ultimate system state is obtained regarding infrastructure failure and community behavior is obtained.

Through a case study done for this work and based on information from Maiduguri, Nigeria, several interesting insights were obtained. First, a system with greater resource capacity is more resilient to disruptions because the effect of resource shortage is mitigated. Second, isolated disruption happening at some "seemingly" critical infrastructures (such as an upstream water treatment plant) may not severely affect the entire system, because the city may be equipped with a considerable amount of independent backup supplies (e.g., commercially-run water wells). Third, under some scenarios, maintaining the functionality of some infrastructures that are struggling to survive may not benefit the society. Shutting them down may help relieve resource competition and guarantee supply of necessary resources to other parts of the system. In general, mutual interactions among infrastructures and communities lead to high-vulnerability risks to the system, especially when the initial disruption is difficult to predict or evaluate in advance. This finding emphasizes the importance of using a holistic model to correctly capture the interdependent relationships between the physical infrastructure systems and the population, when evaluating the system reliability and societal impacts. 
Future research could be conducted in a number of directions. First, the model can serve as a building block to identify the most critical infrastructure in a given system. Based on this, geospatially-informed reinforcement or interdiction strategies can be sought that will best protect an urban system as a whole or at least certain vulnerable communities within it. Second, the model's framework only uses modeled values of time to measure a community's generalized cost; this can be naturally expanded by considering additional cost components (e.g., price of resources). In addition, the model's framework is deterministic; a stochastic infrastructure failure scheme, possibly based on Markovian transitions, may help reveal more insightful and realistic results. Finally, for effective use of this type of model for planning purposes, it will be critical to better understand the sensitivity of model outputs to the level of detail and structural differences in the input data that define the joint infrastructure-community network. Close collaboration between potential end-users in the military planning community and model developers is recommended as model development continues. 


\section{References}

Ahmed, Ibrahim, and Mike Eckel. 2014. "In the Home of Peace, A Sieger of Fear." Voice of America. Available: http://www.voanews.com/MediaAssets2/projects/boko-

haram/index_en.html.

An, S., N. Cui, Y. Bai, W. Xie, M. Chen and Y. Ouyang. 2015. "Reliable Emergency Service Facility Location under Facility Disruption, En-Route Congestion and In-Facility Queuing.” Transportation Research Part E. 82: 199-216. doi: 10.1016/j.tre.2015.07.006.

Buldyrev, S. V., R. Parshani, G. Paul, H. E. Stanley, and S. Havlin. 2010. "Catastrophic Cascade of Failures in Interdependent Networks.” Nature 464 (7291):1025-1028.

"City-wide Motorbike Ban in Maiduguri, Nigeria Aims to Halt Boko Haram Violence." 2011. African Urbanism. Available at: http://africanurbanism.net/2011/07/08/citywide-motorbike-ban-in-maiduguri-nigeria-aims-to-halt-boko-haram-violence/.

Dada, A.C. 2009. "Sachet water phenomenon in Nigeria: Assessment of the Potential Health Impacts.” African Journal of Microbiology Research 3(1): 015-021. ISSN 1996-0808. Available:

https://www.researchgate.net/publication/230760897_Sachet_Water_Phenomenon_in_Nigeri a_Assessment_of_Potential_Health_Impacts.

Electricity Consumers Resources Council (ELCON). 2004. "The Economic Impacts of the August 2003 Backout.” Washington, DC: ELCON.

Haimes, Y., and P. Jiang. 2001. "Leontief-Based Model of Risk in Complex Interconnected Infrastructures.” Journal of Infrastructure systems 7(1):1-12.

Haimes, Y., B. M. Horowitz, J. H. Lambert, J. R. Santos, C. Lian, and K. G. Crowther. 2005. "Inoperability Input-Output Model for Interdependent Infrastructure Sectors. I: Theory and Methodology.” Journal of Infrastructure Systems 11 (2): 67-79.

Haruna, K. January 2015. "Maiduguri, A Troubled Capital City Overtaken By IDPs." Available: http://leadership.ng/features/401050/maiduguri-troubled-capital-city-overtakenidps.

Horner, M. W., and M. J. Widener. 2011. "The Effects of Transportation Network Failure on People"s Accessibility to Hurricane Disaster Relief Goods: A Modeling Approach and Application to a Florida Case Study." Natural Hazards 59 (3): 1619-1634.

Ibeh, N. 18 February 2015. "Nigerian Military Kills Over 300 Terrorists, Captures Many Others.” Available: http://www.premiumtimesng.com/news/top-news/177064-nigerianmilitary-kills-over-300-terrorists-captures-many-others.html.

Johnson, J. and A. Lefebvre. 20 August 2003. "U.S. : Impact of Northeast Blackout Continues to Emerge.” Available: https://www.wsws.org/en/articles/2003/08/blcka20.html. 
Lin, S., B. A. Fletcher, M. Luo, R. Chinery, and S.-A. Hwang. 2011. "Health impact in New York City During the Northeastern Blackout of 2003." Public Health Reports 126(3): 384 .

Minnesota Population Center. 2015. Integrated Public Use Microdata Series, International; Version 6.4. Minneapolis, MN: University of Minnesota.

Motter, A. E. and Y.-C. Lai. 2002 "Cascade-Based Attacks on Complex Networks." Physical Review E 66(6): 065102.

Murdock, Heather. 2014. "Boko Haram's Hometown: Living with the Ugly Nigerian Cult is Not Fun." Published in Christian Science Monitor online at: http://www.csmonitor.com/World/Africa/2014/0517/Boko-Haram-s-hometown-Living-with-theugly-Nigerian-cult-is-not-fun-video.

Myers, N., A. Rhodes, L. Whalley, G. Al-Chaar, J. Roningen, G. Calfas, T. Bozada, T. Hurt, D. Krooks, and D. Morrison. Fortcoming. Understanding the Effects of Infrastructure Changes on Sub-Populations. ERDC Technical Report. ERDCCERL: Champaign, IL.

"Nigeria's Boko Haram Crisis: Cars Banned in Borno State." 24 September 2015. BBC News online. Available at: http://www.bbc.com/news/world-africa-34345953.

Odihi, J.O. 1996. "Urban Droughts and Floods in Maiduguri: Twin Hazards of a Variable Climate.” Berichte des Sonderforschungsbereichs 268: 303-319.

Olugbode, Michael. 2014. "Nigeria: Terror Attachks Plunge Borno Into Blackout.” 2014. Published online at: http://allafrica.com/stories/201408080626.html.

ORNL, Geographic Information Science and Technology. 2010. LandScan. Information at: http://web.ornl.gov/sci/landscan/. Oak Ridge, TN: Oak Ridge National Laboratory, U.S. Department of Energy.

Prezant, D. J., J. Clair, S. Belyaev, D. Alleyne, G. I. Banauch, M. Davitt, K. Vandervoorts, K. J. Kelly, B. Currie and G. Kalkut. 2005. "Effects of the August 2003 Blackout on the New York City Healthcare Delivery System: A Lesson for Disaster Preparedness." Critical Care Medicine 33 (1): S96-S101.

Public Safety and Emergency Preparedness Canada. August 2006. "Incident Ananlysis: Ontario - U.S. Power Outage - Impacts on Critical Infrastructure.” Number IA-06-002. Available: http://cip.management.dal.ca/publications/Ontario\%20\%20US\%20Power\%200utage\%20-\%20Impacts\%20on\%20Critical\%20Infrastructure.pdf.

Rinaldi, S. M., J. P. Peerenboom and T. K. Kelly. 2001. "Identifying, Understanding, and Analyzing Critical Infrastructure Interdependencies.” Control Systems, IEEE 21 (6): $11-25$.

Sahara Reporters. 2015. "Another Boko Haram Fuel Dump Discovered in Maiduguru." Available: http://saharareporters.com/2015/10/01/another-boko-haram-fuel-dumpdiscovered-maiduguri.

Sheffi, Y. 1985. Urban Transportation Networks: Equilibrium Analysis with Mathematical Programming Methods. Englewood Cliffs, NJ: Prentice-Hall, Inc. 
“Terror Attacks Plunge Borno into Blackout.” 2014. Originally published in This Day Newspaper, referenced in Gabu Shehu's column at: http://newsdiaryonline.com/army-garba-shehu/.

U.S. Army. 2014. "The U.S. Army Operating Concept: Win in a Complex World.” TRADOC Pamphlet 525-3-1. Washington, DC: U.S. Army Chief of Staff.

U.S. Army Corps of Engineers, Army Geospatial Center, Warfighter Geospatial Support and Production Directorate, Terrain Analysis Branch (CEAGC-WST). 2013. "Urban Tactical Planner - Digitizing Field Guide, Standard Operating Procedures, and Specifications." (NOTE: For Official Use Only). . 2016. "Urban Tactical Planner." Online source: http://www.agc.army.mil/Media/FactSheets/FactSheetArticleView/tabid/11913/Article/48 0931/urban-tactical-planner.aspx

Wang, X. and Y. Ouyang. 2013. "A Continuum Approximation Approach to Competitive Facility Location Design under Facility Disruption Risks." Transportation Research Part B: Methodological 50:90-103.

Waziri, Muhammad. 2009. Spatial Pattern of Maiduguri City: Researcher's Guide. Adamu Joji Publishers, Kano City.

World Bank. 1996. Implementation Completion Report: Borno State Water Supply Project (Loan No. 2528-UNI). Report No. 15557. World Bank: Infrastructure and Urbana Development Division, West Central Africa Department, Africa Region.

Xie, S., X. Li and Y. Ouyang. 2015. "Decomposition of General Facility Disruption Correlations via Augmentation of Virtual Supporting Stations." Transportation Research Part B 80:64-81.

Zhang, P., and S. Peeta. 2011. "A Generalized Modeling Framework to Analyze Interdependencies among Infrastructure Systems." Transportation Research Part B: Methodological 45(3): 553-579. 


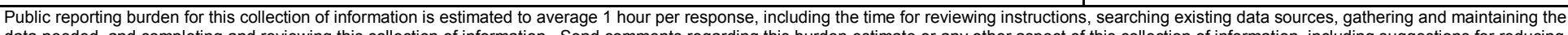

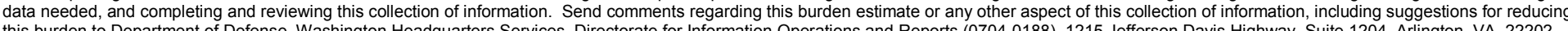

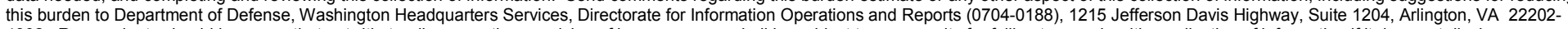

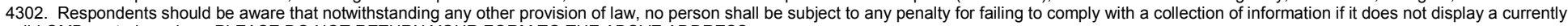
valid OMB control number. PLEASE DO NOT RETURN YOUR FORM TO THE ABOVE ADDRESS.
1. REPORT DATE (DD-MM-YYYY)

\section{REPORT TYPE}
July 2016
Final Technical Report
3. DATES COVERED (From - To)

\section{TITLE AND SUBTITLE}

Assessing Socioeconomic Impacts of Cascading Infrastructure Disruptions in a Dynamic

Human-Infrastructure Network

5a. CONTRACT NUMBER

5b. GRANT NUMBER

5c. PROGRAM ELEMENT NUMBER

6. AUTHOR(S)

Liqun Lu, Xin Wang, Zhaodong Wang, Yanfeng Ouyang,

Jeanne Roningen, Scott Tweddale, Patrick Edwards, and Natalie Myers

5d. PROJECT NUMBER

405479

5e. TASK NUMBER

5f. WORK UNIT NUMBER

7. PERFORMING ORGANIZATION NAME(S) AND ADDRESS(ES)

U.S. Army Engineer Research and Development Center (ERDC)

Construction Engineering Research Laboratory (CERL)

8. PERFORMING ORGANIZATION REPORT NUMBER

PO Box 9005

Champaign, IL 61826-9005

ERDC TR-16-11

\section{SPONSORING / MONITORING AGENCY NAME(S) AND ADDRESS(ES)}

Assistant Secretary of the Army for

Acquisition, Logistics, and Technology

103 Army Pentagon

Washington, DC 20314-1000

10. SPONSOR/MONITOR'S ACRONYM(S)

ASA(ALT)

11. SPONSOR/MONITOR'S REPORT NUMBER(S)

12. DISTRIBUTION / AVAILABILITY STATEMENT

Approved for public release. Distribution is unlimited.

\section{SUPPLEMENTARY NOTES}

\section{ABSTRACT}

The functionality of modern cities relies heavily on interdependent infrastructure systems such as those for water, power, and transportation. Disruptions often propagate within and across physical infrastructure networks and result in catastrophic consequences. The reaction of communities to disasters (e.g., seeking alternatives) may further transfer and aggravate the burden on surviving infrastructures, which may facilitate cascading secondary disruptions. Hence, a holistic analysis framework that integrates infrastructure interdependencies and com-munity behaviors is needed to evaluate a city's vulnerability to disruptions and to assess the impact of a disaster. U.S. Army doctrine requires that commanders understand, visualize, and describe the infrastructure component of the Joint Operating Environment to accomplish the Army's missions of protecting, restoring, and developing infrastructure. To this end, a game-theoretical equilibrium model has been developed in a multilayer infrastructure network, to systematically investigate the mutual influence between the infrastructures and the communities. In this model, two types of infrastructure failure patterns are formulated to capture general network interdependencies; network equilibrium is ex-tended into infrastructure and community systems to address redistribution of demand for life-supporting resources; the societal impact of disasters is estimated based on resource demand loss, cost increase, and total infrastructure failure. A real-world case study was implemented to demonstrate the proposed model and algorithm, and to reveal insights.

\section{SUBJECT TERMS}

Sociology, Military; Infrastructure (Economics) -- Mathematical models; Emergency management; Cities and towns; War; Natural disasters; United States -- Armed Forces -- Stability operations

\begin{tabular}{|c|c|c|c|c|c|}
\hline \multicolumn{3}{|c|}{ 16. SECURITY CLASSIFICATION OF: } & \multirow{2}{*}{$\begin{array}{l}\text { 17. LIMITATION } \\
\text { OF ABSTRACT } \\
\text { UU }\end{array}$} & \multirow{2}{*}{$\begin{array}{l}\text { 18. NUMBER } \\
\text { OF PAGES } \\
70\end{array}$} & 19a. NAME OF RESPONSIBLE PERSON \\
\hline $\begin{array}{l}\text { a. REPORT } \\
\text { Unclassified }\end{array}$ & $\begin{array}{l}\text { b. ABSTRACT } \\
\text { Unclassified }\end{array}$ & $\begin{array}{l}\text { c. THIS PAGE } \\
\text { Unclassified }\end{array}$ & & & $\begin{array}{l}\text { 19b. TELEPHONE NUMBER (in- } \\
\text { clude area code) }\end{array}$ \\
\hline
\end{tabular}

